\title{
Evaluation of Integrated High Temperature Component Testing Needs
}

May 2009

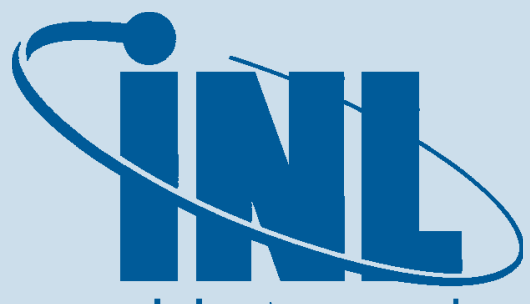

Idaho National Laboratory

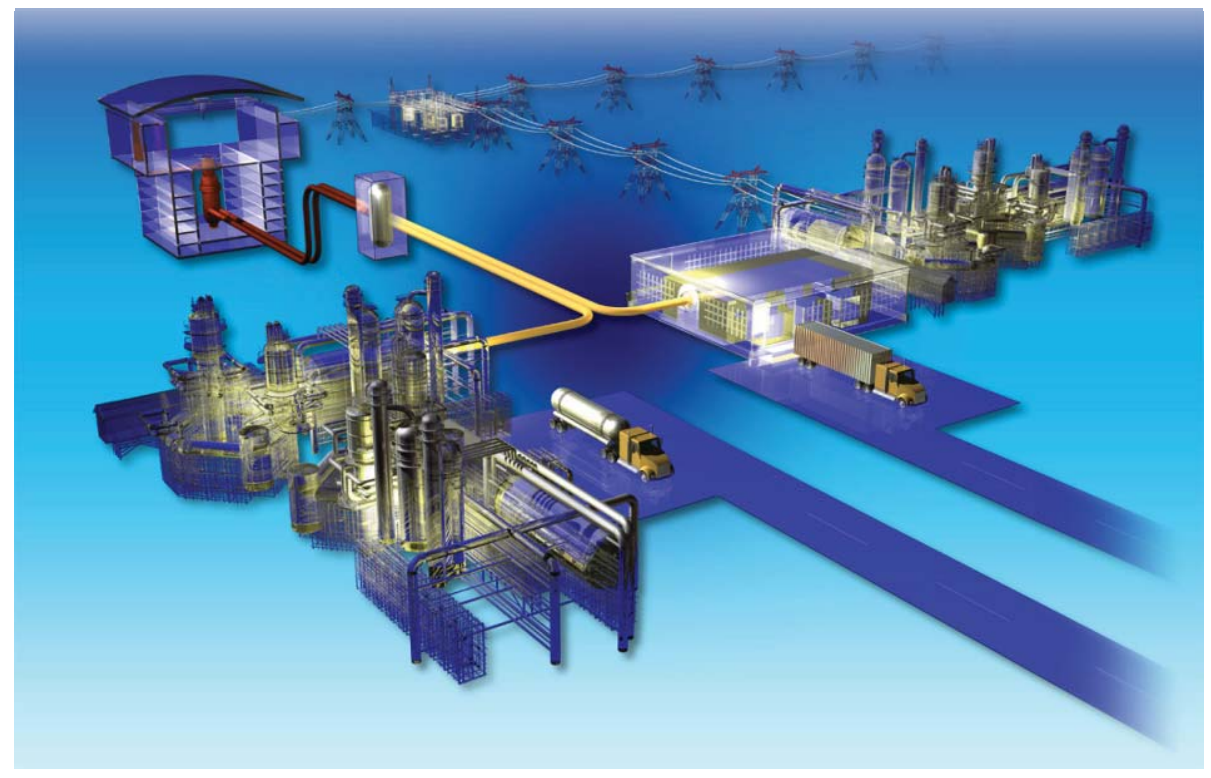

The INL is a U.S. Department of Energy National Laboratory operated by Battelle Energy Alliance. 


\section{DISCLAIMER}

This information was prepared as an account of work sponsored by an agency of the U.S. Government. Neither the U.S. Government nor any agency thereof, nor any of their employees, makes any warranty, expressed or implied, or assumes any legal liability or responsibility for the accuracy, completeness, or usefulness, of any information, apparatus, product, or process disclosed, or represents that its use would not infringe privately owned rights. References herein to any specific commercial product, process, or service by trade name, trade mark, manufacturer, or otherwise, does not necessarily constitute or imply its endorsement, recommendation, or favoring by the U.S. Government or any agency thereof. The views and opinions of authors expressed herein do not necessarily state or reflect those of the U.S. Government or any agency thereof. 


\title{
Evaluation of Integrated High Temperature Component Testing Needs
}

May 2009

\author{
Idaho National Laboratory \\ Next Generation Nuclear Plant Project \\ Idaho Falls, Idaho 83415
}

Prepared for the

U.S. Department of Energy

Office of Nuclear Energy

Under DOE Idaho Operations Office

Contract DE-AC07-05ID14517 



\section{Next Generation Nuclear Plant Project}

\section{Evaluation of Integrated High Temperature Component Testing Needs}

INL/EXT-09-15620

May 2009

Approved by:
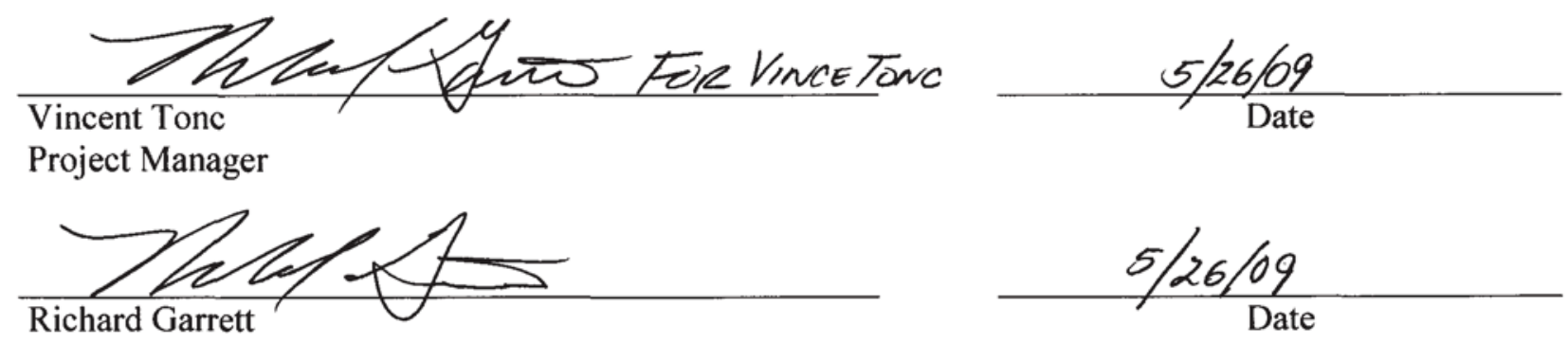

NGNP Engineering Director
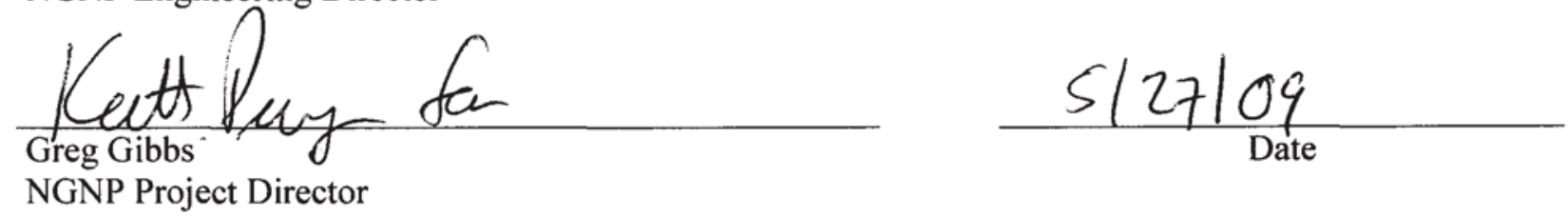



\begin{abstract}
This paper describes the requirements for a large-scale component test capability to support the development of advanced nuclear reactor technology and their adaptation to commercial applications that advance U.S. energy economy, reliability, and security and reduce carbon emissions. This evaluation was based on the requirements identified to-date for large-scale component testing in the Next Generation Nuclear Plant (NGNP) Project. As the lead project in the U.S. Department of Energy Generation IV Nuclear Energy Systems Program, the NGNP Project has the more developed set of requirements, when compared with the other projects in the Program. It is judged that the conclusions reached in evaluating the needs for large-scale testing for the NGNP Project will translate to the other projects because of similar developmental needs such as in prime movers, heat transfer and transport, energy and conversion process development. The evaluation also factored in requirements of the "hybrid" energy systems that apply advanced reactor technology to the processing of fossil feedstock such as biomass and coal for production of cleaner transportation fuels, and relevant industry experience that benefitted from large-scale testing.
\end{abstract}




\section{EXECUTIVE SUMMARY}

\section{Prologue}

This paper summarizes the (1) requirements and bases for large-scale component test capabilities to support the development of advanced nuclear reactor technologies and (2) form of the hardware that has been developed to provide these capabilities. The requirements for the large-scale testing are based on preconceptual and conceptual design work performed in support of the Next Generation Nuclear Plant (NGNP) Project. The NGNP is the lead project of the U.S. Department of Energy (DOE) Generation IV Nuclear Energy Systems (Gen-IV) program with the objective of commercializing high temperature gascooled reactor (HTGR) technology. Given the current maturity of selected NGNP Project technologies, it is necessary to identify high technology risks early to avoid cost overruns and schedule delays later in the project's life cycle.

The need for large-scale testing has evolved from the design data needs (DDNs) identified to-date in NGNP design planning and from the integrated technology development roadmap (TDRM) program developed in collaboration with the applicable reactor suppliers of the NGNP Project. To advance technology maturity and reduce risk, the TDRM combines several levels of research and development (R\&D), analysis, design, and testing for those critical technologies required to support economic, reliable, and safe operation of the HTGR. The NGNP TDRM program includes the widely applied National Aeronautics and Space Administration (NASA) method to assess technology readiness levels (TRLs) and the approach for advancing them. The TDRM process emphasizes testing to validate the understanding and viability of each advanced technology at every phase of its advancement. Industry and DOE experience have also shown that large-scale testing is necessary to prove the viability of critical technologies at full or near full scale prior to installation in the plant so that major cost overruns and schedule delays may be avoided. Although these large component testing capabilities are based on the initial needs of the NGNP Project and the subsequent HTGR fleet deployment, it is anticipated that they will also prove useful in the development of other advanced reactor technologies in the Gen-IV program since they all have developmental needs similar to NGNP (e.g., prime fluid movers, heat transfer). As these programs increase in maturity and the demand for large component testing is reduced, the same capabilities/hardware will play a significant role in the integration of industrial HTGRs. The latter use of these capabilities could reduce the operating costs of the facilities, maintaining it as a user facility.

Integrated large-scale test capabilities are therefore, an important and necessary resource in the development of advanced energy technologies. The application of those technologies is vital to improvement of the long term energy portfolio of the United States (e.g., in economic, environmental, and energy security terms).

\section{Summary}

NGNP is the lead project of the Gen-IV program. The mission of the Gen-IV program includes the development of advanced nuclear energy technologies that will allow the United States to continue to exploit economic, safe, clean, and domestic nuclear energy to meet its energy needs. This program addresses the development of molten salt and lead cooled reactors, supercritical water reactors, sodium fast reactors, and the NGNP Project. The NGNP project has the objective of commercializing the application of HTGR and very high temperature reactor technology. This graphite moderated reactor technology provides higher temperature energy than conventional light water reactors and can be used as a viable and economical substitute for the burning of fossil fuels in a wide range of commercial applications such as producing hydrogen, supplying steam or process heat for a wide range of industrial applications, and high-efficiency electricity in co-generation applications. This technology, when deployed, can mitigate the uncertainty in long term energy availability and costs that have occurred due to 
fluctuations in traditional fossil energy supplies such as oil and natural gas. Deployment of this technology also reduces emissions of greenhouse gases associated with the burning of fossil fuels, conserves our indigenous resources for more productive uses (e.g., feedstock for chemical processing), and reduces our reliance on foreign sources of energy.

The NGNP Project was initiated in accordance with the provisions of the 2005 Energy Policy Act (EPAct). The EPAct charges DOE with the design, development, and construction of a plant that demonstrates the production of hydrogen or electricity, or both, using the HTGR technology in commercial applications. This technology is to be licensed by the Nuclear Regulatory Commission (NRC). To date, the NGNP Project has completed preconceptual design work, initiated conceptual designs, and initiated licensing discussions with NRC for plants with these capabilities. This work has been coordinated by Idaho National Laboratory (INL) under DOE direction.

Over the course of preconceptual and conceptual design work completed for the NGNP Project at the time of this writing, approximately 450 DDNs have been identified to support design, licensing, construction and operation of the HTGR. Eighteen critical structures, systems, and components (SSCs) necessary to successfully design and license the HTGR have also been defined. A critical SSC is one for which significant design development is required because it is a either new technology or a significant extension from current experience with an existing technology. In this regard, the NGNP design extends technologies or develops new technologies in several areas. It will employ gas circulators two to three times larger (11 to $16 \mathrm{MWe}$ ) than those currently in service, (up to $5 \mathrm{MWe}$ ). It will use an indirect heat transfer/transport system with developmental intermediate heat exchanger designs (e.g., compact printed circuit, plate-fin, or welded plate designs), spiral tube heat exchangers, steam generators, piping, and isolation and relief valve designs. A further product of the NGNP preconceptual and conceptual design work included development of a scale of TRLs ${ }^{\mathrm{a}}$ and assessment of the current TRLs for each critical SSC.

Eighteen Technology Development Roadmaps, including detailed plans and schedules, have been developed to address resolution of the DDNs and to advance the technology readiness of critical SSCs as required to support the schedule and commercialization objectives of the Project. To this end, the objective of these roadmaps is to advance the technology of critical components and systems sufficiently for application in the HTGR and to demonstrate reliable performance in commercial applications. The requirements for technology development range from the fundamental level (e.g., starting at the earliest conceptual stages such as for ceramic compact heat exchangers) to more advanced technologies that require a quantum increase in capability to satisfy Project needs (e.g., increasing the capacity of gas circulators, which require application of advanced electro-magnetic bearings and power supply connections). As is necessary in any project that is advancing technology, these roadmaps include combining several aspects of technology development and validation to ensure that the DDNs have been satisfied and that the components and systems that result from this process will support safe, reliable and efficient operation of the plant. As shown in Figure E-1, these aspects include analysis by suppliers and supporting entities (e.g., engineering and technology consultants), research and development (e.g., fuels and graphite qualification, material codification by national laboratories), testing in specialized facilities, (e.g., materials testing by national and other laboratories), testing in supplier facilities, (e.g., bench-scale testing of circulator electromagnetic bearing performance, testing of developmental valve operators) and final proof of principle and design testing at near full scale in a component test capability. Although the advancement of the technology readiness level of an SSC is along a linear scale (1 to 10) the process of

a. The TRL scale was patterned after that developed and used extensively by NASA. It assesses the technical readiness of an SSC within 10 progressive stages of development from preconceptual through conceptual, lab- and bench-scale validation, partial scale component and system testing to full- or near-full-scale testing for final validation of concept prior to installation in the plant (TRL 7 to 8). The ultimate readiness level is reached upon successful operation in the commercial plant. 
advancement is iterative. The testing, analysis and $R \& D$ at each stage of development inform the design for the next stage and so on until the ultimate stage is reached with installation in the plant.

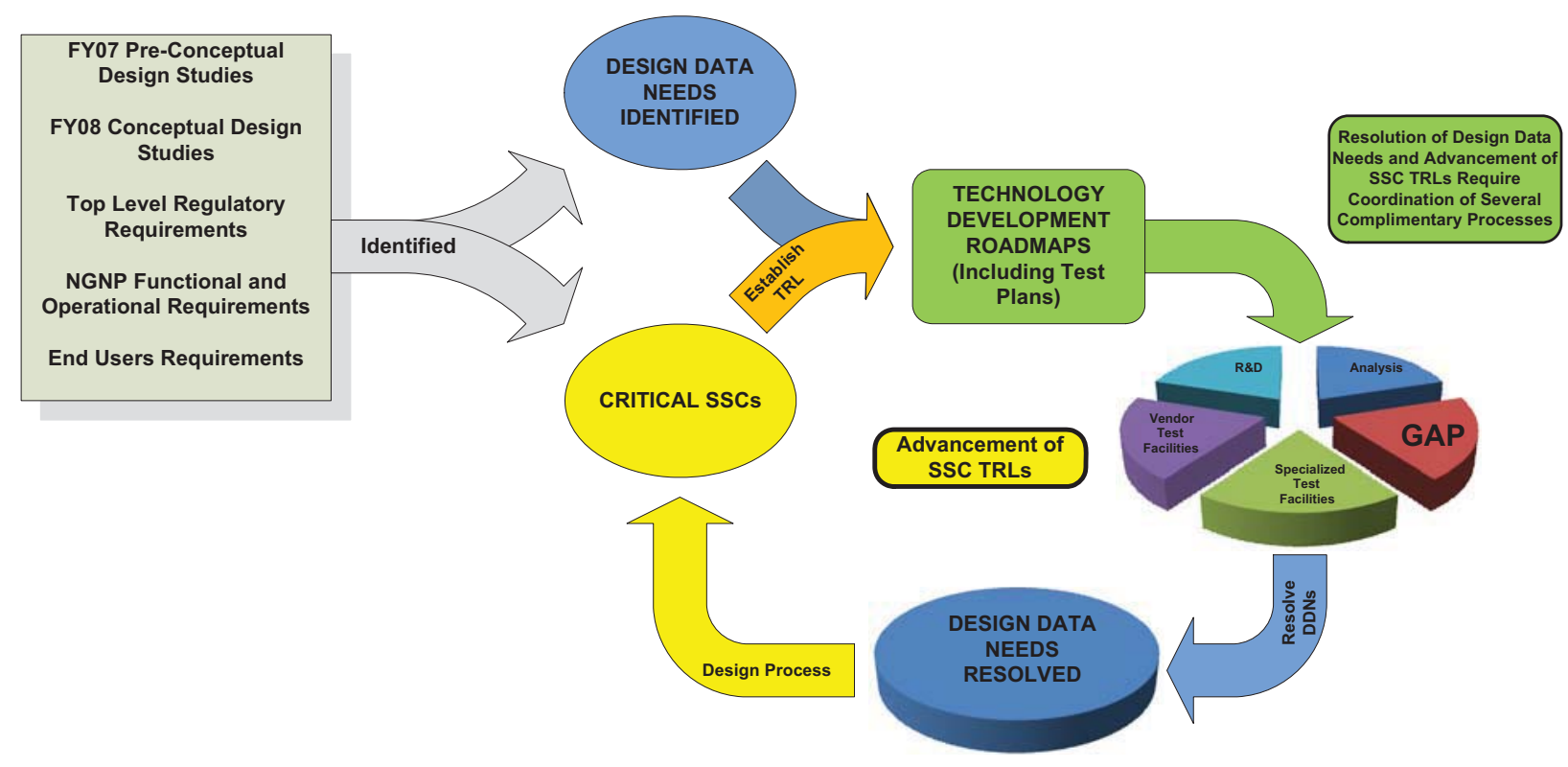

Figure E-1. Combined aspects of technology development and validation.

Approximately 350 separate test requirements have been identified in the TDRMs. Tables A-1 through A-3 in Appendix A summarize the tests identified by the three HTGR suppliers, including the objectives of each test, the test parameters, and the expected location for the testing. Two hundred and sixty of these tests have been slated for completion in specialized test facilities and vendor facilities. These tests are needed to validate the technology at each stage of development so it can be advanced to the next stage. Many of the technologies are starting at TRLs less than 4 or 5, requiring that testing begin at laboratory and bench-scale levels and then progress through higher scales until they are ready for fullor near-full-scale testing. These are the tests performed in the specialized and vendor test facilities, which then prepare the SSC for full- or near-full-scale testing.

The $\sim 75$ tests identified, for which no facilities exist, are needed to ensure that the developmental component and system designs are ready for installation and operation in the plant. Although defined as tests, multiple objectives were included in each test plan and numerous individual tests could be viewed as multiple tests such that the actual number of individual tests identified could be much higher. Successful completion of all aspects of technology development is necessary to reduce risks and achieve successful operation in the plant. The ultimate validation of developmental success prior to installation in the plant is successful operation at full scale.

The studies performed to summarize and develop specific requirements for the testing of NGNP critical SSCs at representative scale also evaluated whether facilities exist that have these capabilities. These studies performed preliminary reviews of the capabilities of existing test loops in the United States, Europe, South Africa, and Russia, and concluded that none of these facilities have the required capabilities. The larger loops ( 10 MWt) are no longer operating and have been dismantled or mothballed. The smaller loops do not have the combined flow, pressure, and temperature capabilities, and are designed for very specialized and focused purposes (e.g., the Helium Test Facility in South Africa). Other alternatives for obtaining the necessary large-scale and integrated testing were also considered. These included: 
1. Do Nothing - no large-scale testing of NGNP critical SSCs except during cold start-up in the plant.

2. Distribute the testing requirements to the component and system vendors as part of the specifications for procurement.

3. Modify existing facilities (mostly overseas) to support NGNP large-scale test needs.

4. Construct a stand-alone facility to house and operate test loops designed to meet NGNP large-scale testing needs.

Evaluation of the above alternatives and any others not yet identified for establishment of the component test capability will be developed following the approval of this Mission Needs (critical decision [CD]-0) and submitted as part of the CD-1 approval request.

The development of a large-scale component test capability also complements the objectives of the Battelle Energy Alliance/INL Energy Security Initiative, which includes the Hybrid Energy System development program. This program is undertaking accelerated integration of nuclear power, including the HTGR technology, with broader energy system development such as production of synthetic transportation fuels derived from coal and biomass. This program takes advantage of the non-carbonemitting characteristics of nuclear power energy for the production of very low carbon electricity, transportation fuels, and process heat. The objectives of the Hybrid Energy System Program are to develop and demonstrate the overall efficiency, environmental performance, and economic benefit of these systems to the United States. An important element of this program is the Hybrid Systems Testing (HYTEST) Laboratory, which will be developed to advance critically enabling engineering research in the areas of feedstock preparation, heat transfer, fuels and product synthesis, byproduct management, and advanced diagnostics and controls. The HYTEST Laboratory will also address component/system integration and dynamics challenges. Many of these component and process level challenges are common with NGNP needs. The projects will be leveraged to support NGNP test program needs as shown in Figure E-3.

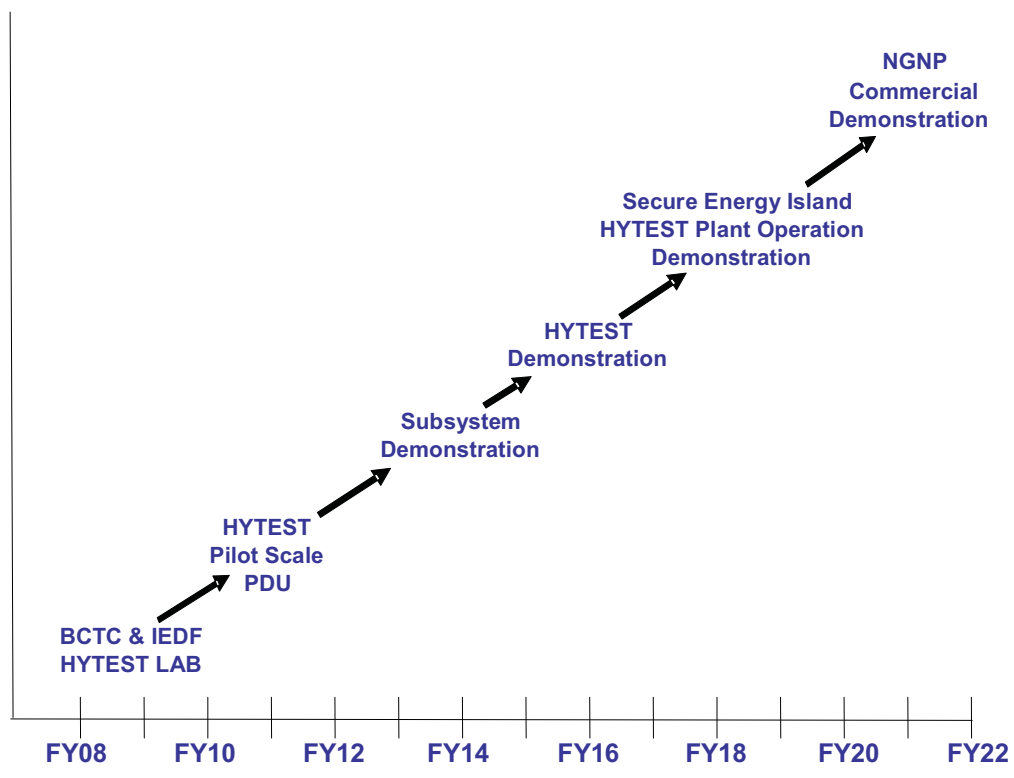

Figure E-3. HYTEST component and process testing scales.

Project management principles and risk reduction practices emphasize that technology be well understood before starting construction and/or operation of major developmental projects. Industry experience demonstrates the consequences of not following these principles. Relevant examples include 
U.S. Government Accountability Office assessments of DOE projects that have had significant cost and schedule overruns. These assessments cited the following, in part, as contributors to these overruns:

- Approval of construction activities before final designs were sufficiently complete, ineffective project reviews

- Poor contractor management...owing in part to technology integration problems

- Proceeding with technology that is not sufficiently developed

- Technology had not been used previously in this application and it did not work in tests as expected, even after construction had already begun.

The Government Accountability Office made the following recommendation:

To improve oversight and decision making for DOE's major construction projects, we are recommending that the Secretary of Energy evaluate and consider adopting a disciplined and consistent approach to assessing TRLs [the NASA approach was cited as an example] for projects with critical technologies.

As noted, this is the basis and objective of the Technology Development Roadmaps developed for the NGNP Project.

Figure E-4, excerpted from an Electric Boat presentation, illustrates the need for early detection of defects in the design process. It shows that design decisions made early in the process have a major impact on the total project cost; for example, decisions in conceptual design account for $70 \%$ of the committed cost of the project. The redline shows the consequence of late detection of defects in the design. Correcting defects in the development phase cost 100 times the cost of correcting them in the conceptual design phase and 1,000 times in the production phase. Clearly, successful execution of the TDRM process, including testing, is critical to avoiding late detection of defects in the design and maintenance of the project on schedule and within budget. 


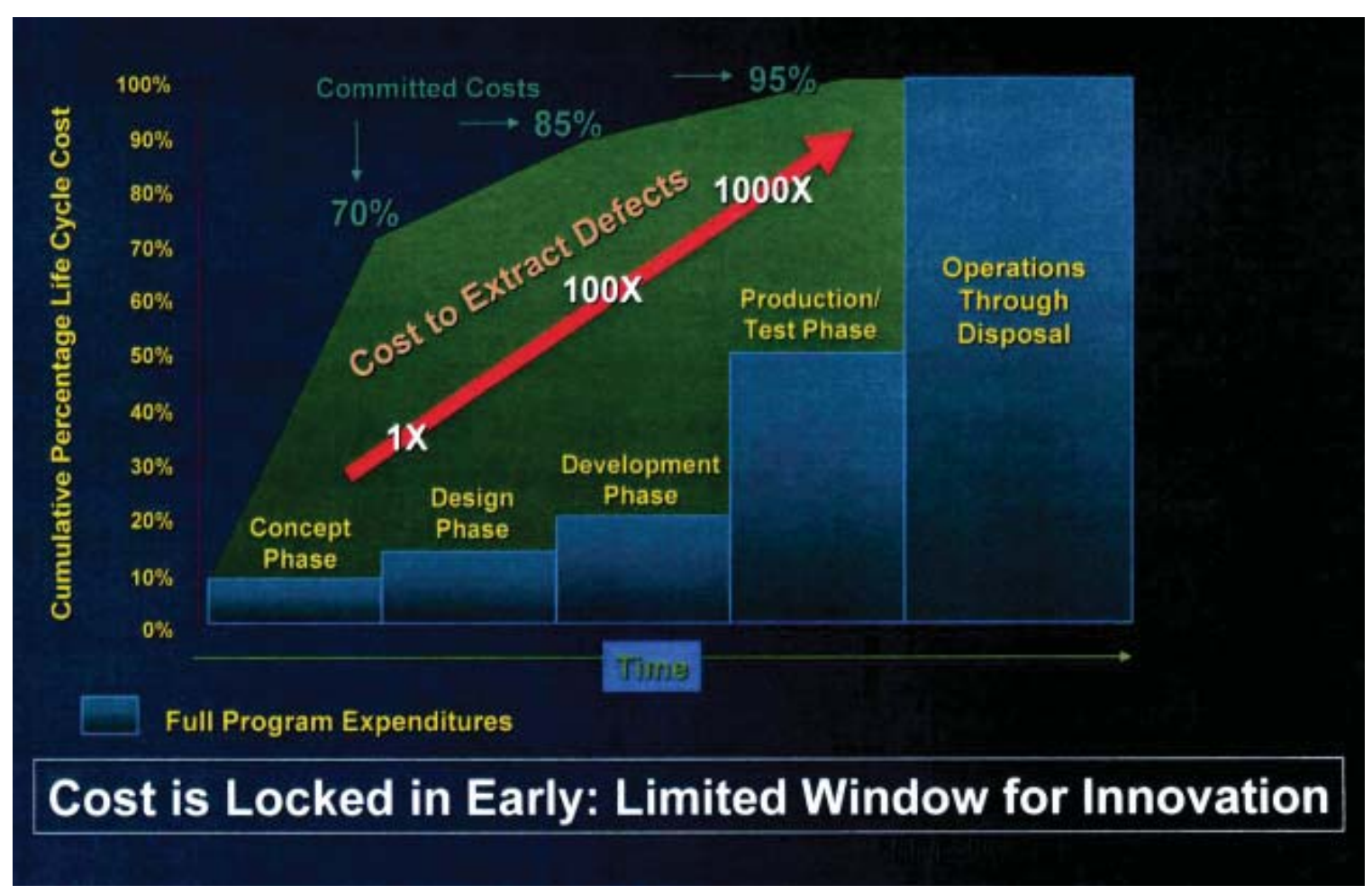

Figure E-4. Innovation impact on program cost.

In summary, this paper describes the requirements for a large-scale component test capability to support the development of advanced nuclear reactor technology and their adaptation to commercial applications that advance U.S. energy economy, reliability, and security and to reduce carbon emissions. This evaluation was based on the requirements identified to date for large-scale component testing in the NGNP Project. As the lead project in the Gen-IV program, the NGNP Project has the more developed set of requirements when compared with the other projects in the program. It is judged that the conclusions reached in evaluating the needs for large-scale testing for the NGNP Project will translate to the other projects because of similar developmental needs such as in prime movers, heat transfer and transport, and energy conversion process development. The evaluation also factored in requirements of the hybrid energy systems that apply advanced reactor technology to the processing of fossil feedstock, such as biomass and coal, for production of cleaner transportation fuels and relevant industry experience that benefitted from large-scale testing.

Although the large-scale component test capability is essential in the short term for expedient development and application of the advanced nuclear reactor technologies, it has an equally important long-term role in supporting the continuing development of the full potential of these technologies by supporting advances in their capabilities and application to evolving and wider ranges of applications. The NGNP Project is only the beginning of the development of advanced nuclear reactor technologies and their expanded uses. Individually and in sum, the development and commercialization of advanced nuclear reactor technologies will introduce economical, reliable, and sustainable resources to the energy supply portfolio of the country. Other significant benefits of this energy supply to the country and environment are that it does no release greenhouse gases; uses domestically supplied fuel; and replaces the burning of fossil fuels, thereby improving our energy security by reducing our dependence on offshore sources and effectively utilizing our domestic sources of fossil fuels. The Gen-IV and hybrid nuclear programs discussed herein, including NGNP, have only begun to develop and exploit the benefits of these technologies. A large-scale component test capability that can be accessed by domestic and international 
supporters and developers of advanced nuclear reactor technology provides an essential resource for ensuring the expeditious and continued development of these important technologies. 


\section{CONTENTS}

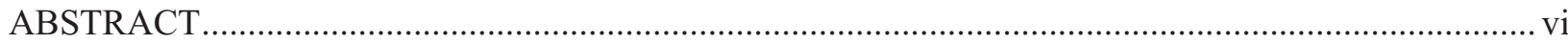

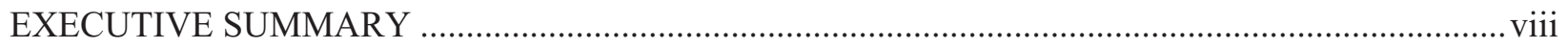

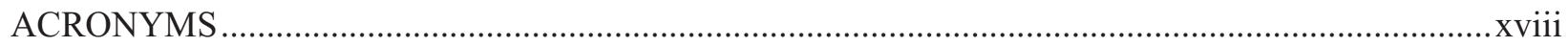

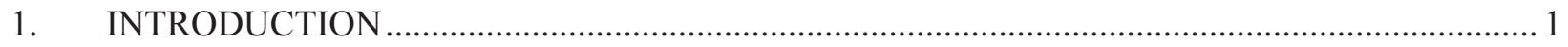

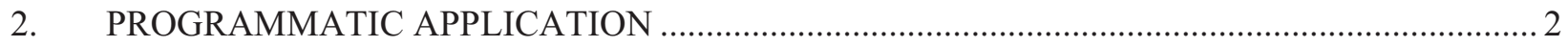

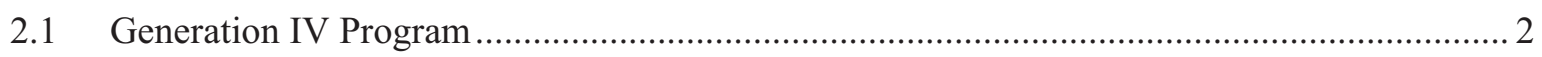

2.2 Next Generation Nuclear Plant ............................................................................... 3

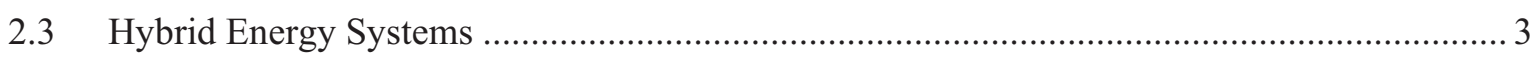

3. COMPONENT AND SYSTEM DEVELOPMENT NEEDS...................................................... 6

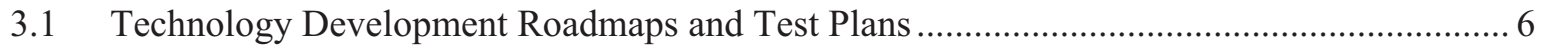

3.2 NGNP Design Data Needs Identified in the NRC PIRT Process ......................................... 6

3.3 Hybrid Energy System Initiative Large-Scale Testing Needs ............................................. 7

3.4 Testing Needs of Critical NGNP Project SSCs............................................................. 7

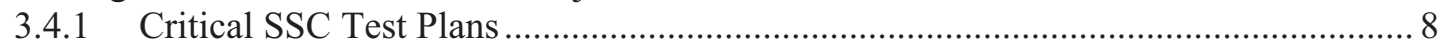

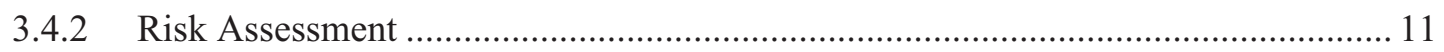

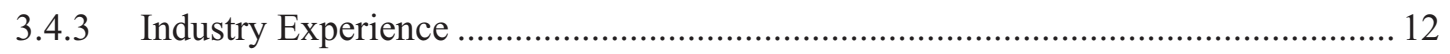

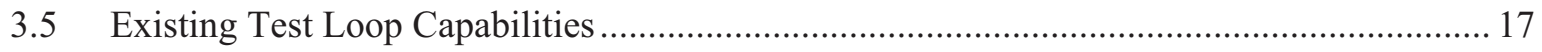

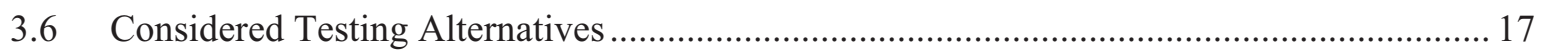

3.7 Additional Considerations for Conducting the Alternatives Analysis ….............................. 17

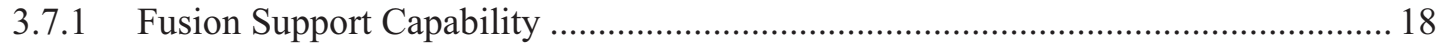

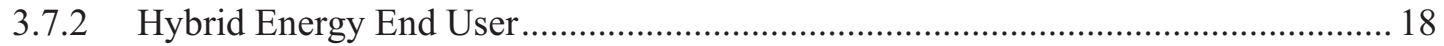

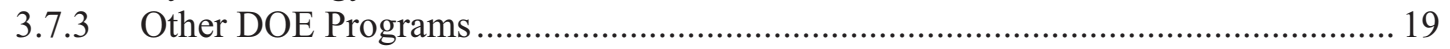

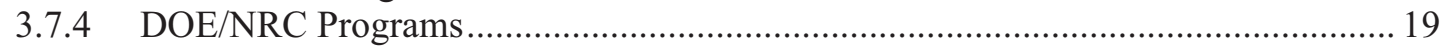

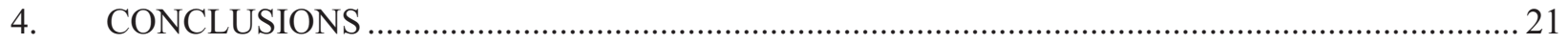

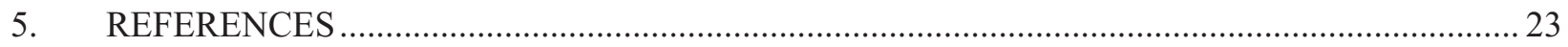

Appendix A-Summary of Testing Requirements and Recommended Test Locations.......................... 25

Appendix B —-Hybrid Energy Systems Testing Laboratory (HYTEST) ............................................ 41

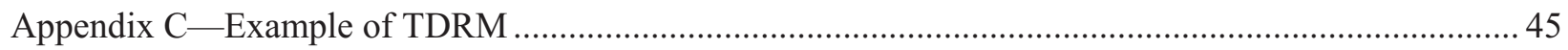

\section{FIGURES}

Figure E-1. Combined aspects of technology development and validation. ..........................................

Figure E-3. HYTEST component and process testing scales. ............................................................

Figure E-4. Innovation impact on program cost. ..............................................................................ii

Figure 1. HYTEST component and process testing scales. ................................................................ 4 
Figure 2. Illustration of radial heat transfer path from fuel elements to reactor cavity cooling system.

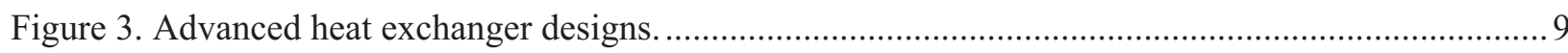

Figure 4. Illustration of an advanced steam generator design............................................................... 9

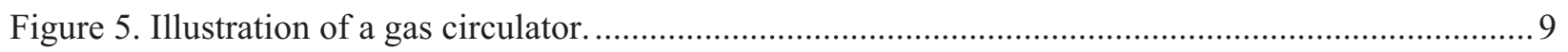

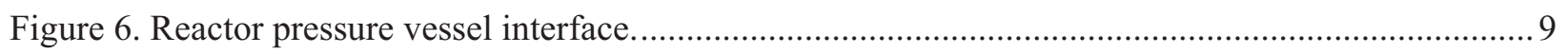

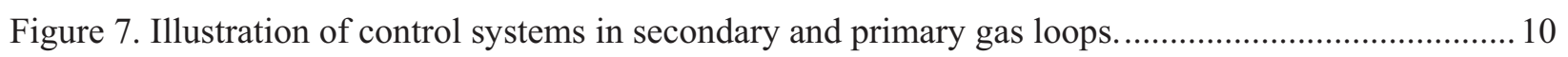

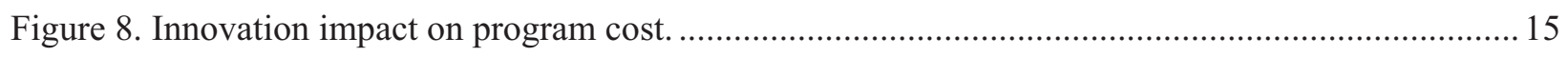

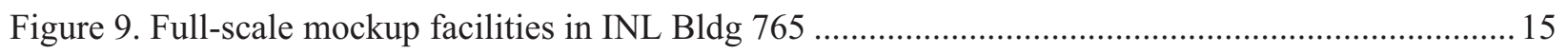

\section{TABLES}

Table 1. Summary of worldwide existing and planned fluid flow test facilities. 16

Table A-1. Summary of AREVA Identified Test Requirements and Recommended Test Locations.

Table A-2. Summary of PBMR Identified Testing Requirements and Recommended Test Locations. 30

Table A-3. Summary of GA Identified Testing Requirements and Recommended Test Locations............34

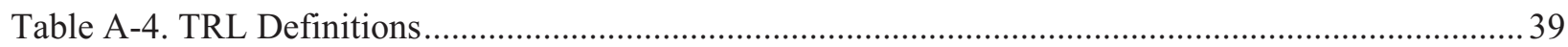

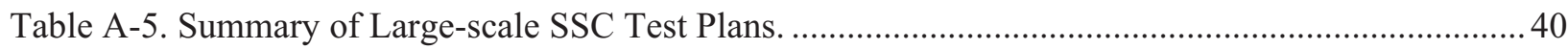




\section{ACRONYMS}

DDN design data need

DOE U.S. Department of Energy

DOE-NE DOE Office of Nuclear Energy

EPAct Energy Policy Act of 2005

GAO Government Accountability Office

Gen-IV Generation IV Nuclear Energy Systems program

HTGR high temperature gas-cooled reactor

HYTEST Hybrid Energy Systems Testing (Laboratory)

I\&C instrumentation and control

IHX intermediate heat exchanger

INL Idaho National Laboratory

ITP in-tank precipitation

NASA National Aeronautics and Space Administration

NGNP Next Generation Nuclear Plant

NRC Nuclear Regulatory Commission

OKBM Experimental Machine Building Design Bureau

PBMR Pebble Bed Modular Reactor

PIRT Phenomena Identification and Ranking Table

$\mathrm{R} \& \mathrm{D} \quad$ research and development

SSC structures, systems, and components

TDRM Technology Development Roadmaps

TRL technology readiness level 


\section{Evaluation of Integrated High Temperature Component Testing Needs}

\section{INTRODUCTION}

This paper summarizes the need for a U.S.-based, large-scale component test(ing) capability to support the development of advanced nuclear reactor technology. This need was demonstrated by reviewing the testing requirements identified for the Next Generation Nuclear Plant (NGNP) Project - the lead project in the U.S. Department of Energy's (DOE's) Generation IV Nuclear Energy Systems (Gen-IV) program. An essential step in the commercialization of advanced nuclear reactor technology is large-scale testing to demonstrate performance of advanced systems and components when unacceptable risks cannot be mitigated adequately by analysis, simulation, or small-scale tests. A widely accessible large-scale component testing capability will permit new designs, new materials, and new instrumentation and control systems to be validated, fabricated, and tested at appropriate scale before placement into nuclear service. Testing is thus a fundamental element of effective risk management for technology development programs in that it helps identify defects throughout the design process, thereby addressing and mitigating risks associated with project cost and schedule and the performance risks associated with these defects. The consequences of not applying effective testing in technology development programs have been demonstrated by many DOE programs that have experienced significant cost and schedule overruns. This capability is needed by suppliers of equipment and services in the nuclear industry to facilitate the re-emergence of domestic nuclear components and system suppliers.

This paper summarizes the Gen-IV program with emphasis on the NGNP Project and its status and the technology development, including testing; risks addressed and mitigated by specific testing requirements identified to-date, and basic project management principles and industry experience that demonstrate the need and benefits of large-scale testing to the success of developmental projects. 


\section{PROGRAMMATIC APPLICATION}

The need for a large-scale component testing capability derives from a broad range of advanced nuclear energy technology development programs and U.S. energy security initiatives. The elements of these programs, which establish the specific requirements for large-scale component testing, are summarized in this section.

\subsection{Generation IV Program}

The mission of the DOE Office of Nuclear Energy (NE) includes the development of advanced nuclear energy technologies that will allow the United States to continue to exploit safe, clean, and expanded uses of domestic nuclear energy to meet its energy needs. ${ }^{1}$ Ongoing programs supporting this mission include the Department's Generation IV Nuclear Systems Initiative, which supports the development of advanced nuclear reactor technologies. The program goals include: ${ }^{2}$

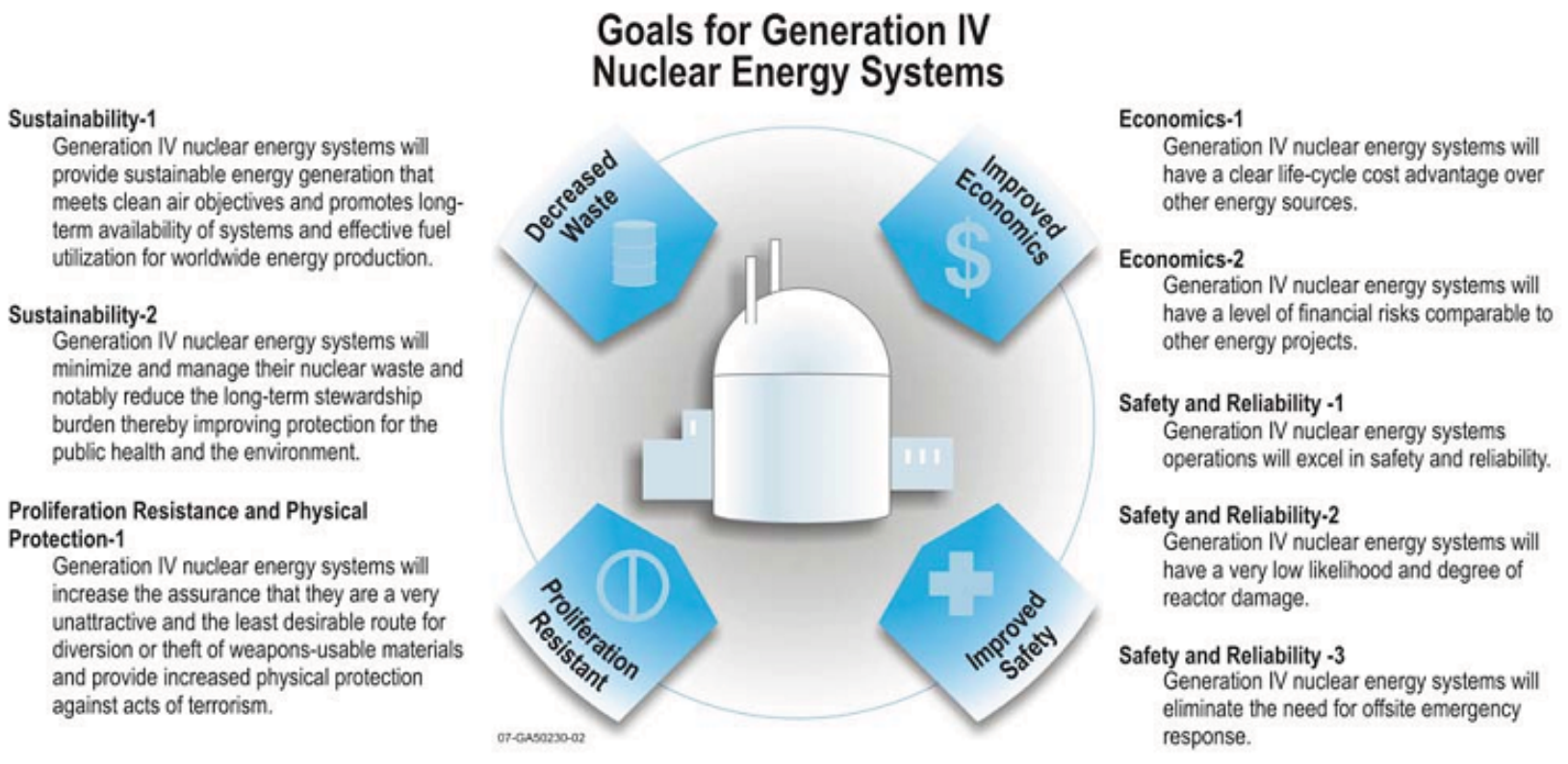

To these ends, the following technologies have been selected for development ${ }^{3}$ :

- Gas-cooled fast reactor system

- Lead-cooled fast reactor system

- Molten salt reactor system

- Sodium-cooled fast reactor system

- Supercritical-water cooled reactor system

- Very high temperature reactor system.

The Gen-IV Implementation Plan concluded that:

“...as priority 1, we should: Develop a Next Generation Nuclear Plant to achieve economically competitive energy products, including electricity and hydrogen ...

The highest priority is on the development of a more economically competitive system to meet growing energy demand and maintain the share of nuclear energy in the United 
States. Successful development of an economically competitive nuclear energy system will be a major focus of the Office of Nuclear Energy, Science and Technology through the development of a VHTR-based system designed to produce cost-effective electricity, and which offers the potential to produce commercial quantities of hydrogen in the future. This technology is known as the Next Generation Nuclear Plant (NGNP). The Department expects to complete key R\&D for the NGNP by about $2010 .{ }^{4}$

\subsection{Next Generation Nuclear Plant}

DOE-NE initiated the NGNP Project for the development of high temperature gas-cooled reactor (HTGR) technology for producing electricity and hydrogen under the provisions of the 2005 Energy Policy Act (EPAct). ${ }^{5}$ Although the EPAct focuses on the production of electricity and hydrogen, the HTGR technology will also have other commercial applications such as supplying steam and hot gas to chemical and refining processes and producing steam, electricity, and hydrogen to support oil sands and oil shale extraction processes. ${ }^{6}$ Process heat, hydrogen, oxygen, and electrical power are also beneficial to the conversion of coal to synthetic fuels and chemicals. ${ }^{7}$ At the date of this writing, the NGNP Project has completed preconceptual design and initiated research and development (R\&D) programs in fuels, materials, and methods. ${ }^{8}$ This design work has been completed primarily by three teams of companies headed by the three principal suppliers of the HTGR technology - General Atomics, AREVA, and the Republic of South Africa's Pebble Bed Modular Reactor (PBMR) - referred to herein as the "supplier teams."

In the course of completing this work, specific design data needs (DDNs) have been identified to advance the designs. A significant fraction of the needs are associated with developing first-of-a-kind advanced structures, systems, and components (SSCs) and the practical integration of these components into robust systems. The advancement of the technological readiness of these SSCs requires the systematic application of testing to validate the designs, starting with laboratory bench-scale to large-scale prototype testing prior to installation in the plant. Since these are the contemporary requirements of the Gen-IV program, the testing requirements identified to-date for the NGNP Project are used herein as bases for establishing the requirements for a large-scale component test capability.

It is judged that the testing needs of other Gen-IV advanced reactor technologies will align generically with those of NGNP, including the development of prime movers, heat transfer and transport equipment, advanced instrumentation and controls, and the qualification of energy conversion technologies. It is also true that a test facility intended to support the development of advanced technologies must be adaptable to varying interface and support requirements because, by definition, advanced technologies will not be at a stage of technology readiness or design development at which specific and rigid test capabilities can be defined. Accordingly, although the mission needs and potential characteristics of the test capability are focused on the NGNP Project requirements herein, the specific characteristics of a test capability must be flexible enough to support other advanced reactor technologies.

\subsection{Hybrid Energy Systems}

The NGNP Project has a role in supporting Idaho National Laboratory's (INL's) initiative to develop hybrid energy systems. The objective of the initiative is to accelerate the application of nuclear energy into broader energy application markets, simultaneously advancing economic competitiveness, energy resource security, and environmental sustainability. Alternate nuclear applications of primary interest include nuclear-fossil-renewable energy hybrids for low-carbon transportation fuels, process heat, and chemicals. Nuclear energy integrated into advanced hybrid systems opens several intriguing opportunities to advance energy security. Nuclear power can be used to produce clean power that can then operate the energy intensive equipment needed in oil refining and unconventional fossil energy extraction. It can also 
be used to split water into molecular oxygen and hydrogen using electrolysis or one of several possible thermal chemical processes. This hydrogen and oxygen can then be used with nuclear heat and power to enhance the conversion of biomass and fossil fuels into synthetic transportation fuels, substitute natural gas, and other vital chemical products and commodities. Properly designed hybrid systems can also serve as a platform to bring intermittent renewable energy such as wind into production by supplying a platform that stabilizes electrical grids by optimizing what energy products are produced (e.g., liquid fuel, electricity, process heat) based on need. In view of present concerns for secure energy sustainability and climate control, a program for nuclear-driven energy systems development and commercialization is essential. This program will expand the commercial uses of nuclear energy to supply high temperature process heat to traditional processes or manufacturing operations. To support this program, INL is establishing a Hybrid Energy Systems Testing (HYTEST) Laboratory that will be used to acquire performance data, identify scalability issues; quantify technology gaps and integration needs for various hybrid or other energy systems; and provide infrastructure to develop solutions in the following functional areas as shown in Figure 1:

- Feedstock Processing, including resource extraction, and supply

- Heat Transfer/Energy Integration

- Byproduct Management

- Product Synthesis

- $\quad$ System Monitoring, Diagnostics, and Controls.

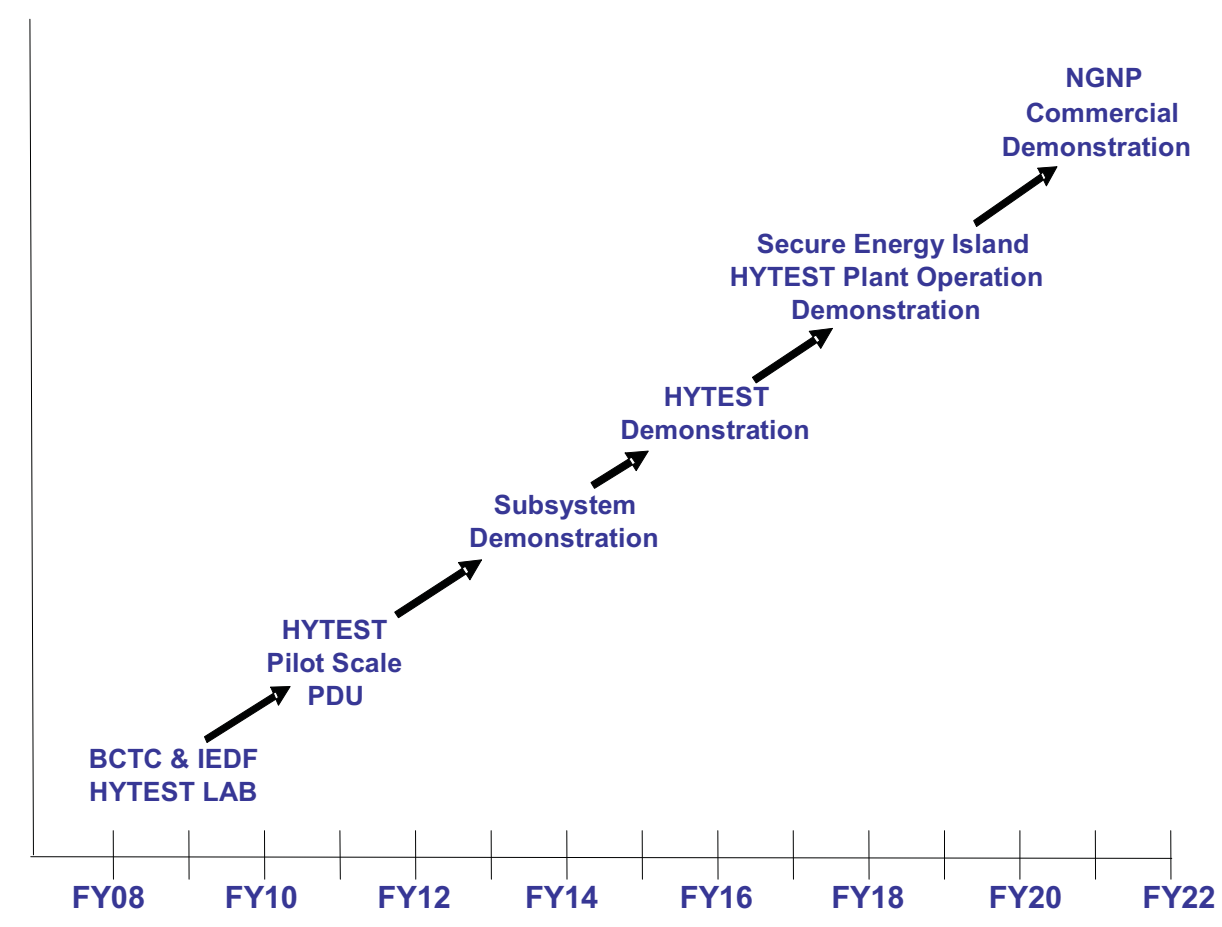

Figure 1. HYTEST component and process testing scales.

The NGNP large-scale component test capability is a key factor in the planning of this program (a summary of HYTEST program is included in Appendix B). The HYTEST program will effectively carry new technology applications and systems integration concepts through DOE Technology Readiness Levels (TRL) by establishing testing and demonstration laboratories at three locations. In FY 2009, INL will setup and integrate lab and bench scale components for each of the four functional test areas at the Bonneville County Technology Center and the Idaho Engineering Development Facility. A 
reconfigurable pilot-scale HYTEST will be installed at the INL in a facility with the forthcoming Office of Biomass Programs Process Development Unit Laboratory, which will be available for testing beginning in FY 2011. This facility will combine the five functional areas in one location, incorporating high temperature heat transfer loops and heat exchangers to demonstrate nuclear heat transfer to fossil fuel and biomass feedstock conversion reactors. Engineering-scale tests will lead to commercial HYTEST demonstrations in a secure energy island demonstration platform. The combined activities will optimize design, reduce operational risk and lead to more solutions for reliable and safe operation of highly coupled nuclear thermal-chemical hybrid energy plants. In order to optimize system design and integration, to supplement current technology and to ensure reliable and safe operation, concurrent development and evaluation of new process instruments, supervisory control systems and virtual plant simulators will be required, all of which will need validation at full or near full scale. 


\section{COMPONENT AND SYSTEM DEVELOPMENT NEEDS}

\subsection{Technology Development Roadmaps and Test Plans}

The NGNP Project has initiated the preparation of Technology Development Roadmaps (TDRMs) for critical SSCs as part of a Project Risk Management Program. These roadmaps, have been developed by the three reactor supplier teams. The TDRMs document the current state of the TRL of critical SSCs for NGNP and the steps necessary to advance the TRLs of these SSCs to the level established as being necessary for installation and operation in the plant. ${ }^{9,10}$ Certain elements of these roadmaps include the identification of relevant DDNs and the development of design, simulation, and testing required to address them. Where testing is identified, test plans are formulated. These test plans include the specific test requirements and a recommended location for the test. In cases where large-scale testing is identified as required and no known facility has the capability to perform the testing, the assumption is made that such a capability gap would be filled as part the technology maturation effort in support of NGNP. An example of the TDRM for an intermediate heat exchanger (IHX) is provided in Appendix C. A review of this TDRM illustrates that the testing requirements progress from bench scale to, where required, largescale prototype testing as the technology readiness of the design advances. The overall TDRM process has identified over 75 multi-objective tests that require large-scale testing to complete the maturation process of technologies associated with NGNP's 18 critical SSCs. These tests provide the final validation of the design at appropriate scale to establish confidence in the reliability and performance of the component or system prior to installation in the plant. Because these components or systems are tested at scale, the tests also (1) establish that material sources and suppliers exist for the component or system, (2) confirm fabricability, (3) confirm that interfaces can be met in an integrated system, and (4) provide an effective mechanism for developing and proving procedures and criteria to satisfy prestartup and operational inspection and test program requirements.

Since the NGNP is in the initial phases of conceptual design, it is reasonable to expect that additional tests requiring large-scale testing facilities will be identified as the designs progress. Later sections summarize the nature of the tests identified to-date and discuss risks that will be mitigated by performance of this level of testing. The following sections discuss other sources of potential testing requirements for the NGNP Project.

\subsection{NGNP Design Data Needs Identified in the NRC PIRT Process}

Potential additional sources of DDNs are issues raised during the licensing process with the Nuclear Regulatory Commission (NRC). In late FY 2007 and early FY 2008, the NRC initiated the Phenomena Identification and Ranking Table (PIRT) process for the NGNP Project. ${ }^{11}$ To ensure that each of the reactor suppliers considered the PIRT identified issues, each of them were tasked to provide a reconciliation of their associated DDNs against those issues included in the NRC developed PIRT. As of the date of this paper, AREVA and General Atomics have completed their reconciliation reviews. ${ }^{12,13}$ As stated in Reference 13, "The PIRT process is an NRC protocol for providing an expert assessment of safety-relevant NGNP phenomena and for assessing NRC's R\&D needs [i.e., NRC's perception of the safety-related Design Data Needs (DDNs) for the NGNP]." This process, therefore, provides valuable insights into the potential impact of the NRC review process on identifying new DDNs. Reference 13 had the objective of determining "...the extent to which the DDNs identified by GA for its NGNP preconceptual design address the issues raised in the NRC PIRTs, (i.e., to determine if there are any significant technology "gaps" in the DDNs and/or in the planned technology programs)." A similar evaluation is scheduled for completion by Westinghouse Electric Corporation/PBMR in early 2009.

The principal focus of the PIRT process is on nuclear safety issues associated with the reactor fuel and core materials for which there are extensive programs in place such as the NGNP Project advanced 
gas reactor, advanced graphite capsule, high temperature materials, and methods R\&D programs [Ref 13]. Reference 13 points out that there are no significant gaps between DDNs identified in the PIRT process and those identified to date in the NGNP Project design process. Areas where potential gaps may exist were considered as design related with no significant technology development required. Areas that could present licensing risks to the project are associated with safety evaluations and qualification of fuel, graphite, and high-temperature materials. These are being addressed in the NGNP R\&D programs, which have been identified and are implementing testing programs to address these areas.

As part of the NGNP licensing strategy, an extensive preapplication review process is being initiated with the NRC to provide early identification of issues for which additional qualification and testing work may be required. There is the potential, therefore, that additional testing requirements may develop during this process.

\subsection{Hybrid Energy System Initiative Large-Scale Testing Needs}

The hybrid energy systems program plan includes progressively larger scale and integrated testing to advance the technology readiness of components and systems to the level required for commercial application. As discussed above and shown in Appendix B, the proposed NGNP component test capability is a critical element in this plan with each program element leveraged against one another. As this program and the NGNP Project progress, the specific requirements for large-scale component test capabilities will be coordinated, thus maximizing the opportunity for leveraging life-cycle cost-savings.

\subsection{Testing Needs of Critical NGNP Project SSCs}

An objective of the majority of the Gen-IV advanced reactor technologies is to use heat transport fluids that can operate at higher temperatures for improved plant efficiency and which allow adoption of the technology to broader commercial applications that require higher temperatures such as efficient hydrogen production. This is a principal objective of the NGNP Project for the HTGR technology. The development of the materials, components and systems required to transport the energy from the reactor to the energy conversion system at the higher temperatures is one of the more challenging technical issues and dominates the nature of the Critical SSCs for NGNP. It is judged that this will also be a critical developmental area for the other advanced technologies once the state of development of these technologies advances to where NGNP is today. The work completed by NGNP in developing materials and components capable of operating at high temperature should spring board similar developments for these other technologies.

The NGNP Project has defined critical SSCs as those for which development is required to ensure their reliability and performance in NGNP and/or for qualification to support plant licensing. ${ }^{9}$ This includes SSCs for which there is no relevant prior operating experience or for which the NGNP plant conditions represent an extrapolation from the prior experience that diminishes confidence in the reliability and performance of the SSC. The TDRMs for these critical SSCs identify the testing required to advance their TRL to the level required for installation in NGNP. Key components that require largescale testing include:

- Reactor internals

- IHX

- Ducting and insulation

- Mixing chambers

- Steam generator

- High temperature valves 
- Specific application high temperature instrumentation

- Contaminated gas purification loop

- Special application for gas speciation monitors

- Industrial hydrogen generation and storage components and

- Helium circulators.

The following section discusses those critical SSCs for which large-scale testing is required and for which no current location has been identified. These tests are used to frame the scope of the component test capability gap.

\subsubsection{Critical SSC Test Plans}

Tables A-1, A-2, and A-3 in Appendix A identify the specific test plans identified to date and associated with the critical SSCs as identified in work conducted by AREVA, PBMR, and the General Atomics support teams, respectively. ${ }^{9}$ The tables show the test plans required to progress the TRL for each Critical SSC to a Level 8, which is required for installation in NGNP, and the recommended locations for each test. The figures have been color coded to identify those test plans that require a largescale test capability. Table A-4 summarizes the TRL definitions. Table A-5 presents only those test plans requiring a large-scale test capability. Advancement to TRL 7 requires integrated testing in operational environments. This testing is to be completed at full scale or an appropriate scale representative on a technical basis of the scale of the components to be installed in the plant. The specific test objectives, conditions, data collection requirements and suggested location for each of the tests are in the test plans referenced in Table A-5 and which are found in Reference 9.

The objectives of these test plans can be grouped into a few categories:

- Confirmation of the thermal hydraulic performance at scale to validate models and to support completion of analyses such as the radial heat transfer path from the fuel elements to the reactor cavity cooling system considering gap conductance, bypass flows, fuel and reflector block conduction, core barrel emissivity, etc., as shown in Figure 2.

- Confirmation of the mechanical performance and system interfaces under normal and accident operating conditions at scale (e.g., testing of control rod full length guide tubes and control rods at temperature and pressure, operation and leak tightness of valves at temperature, pressure and pressure differential).

- Demonstrate the performance, reliability, and viability of interfaces for advanced heat exchanger designs such as shell and spiral tube and compact as shown in Figure 3 at scale in integrated subsystem tests under normal operating and abnormal operating conditions, (e.g., higher primary to secondary pressure differential, rapid thermal and pressure transients conditions).

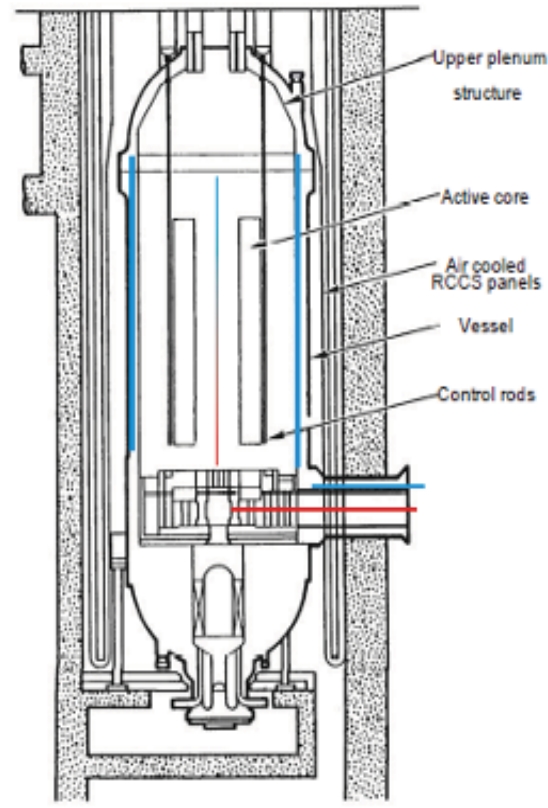

Figure 2. Illustration of radial heat transfer path from fuel elements to reactor cavity cooling system. 

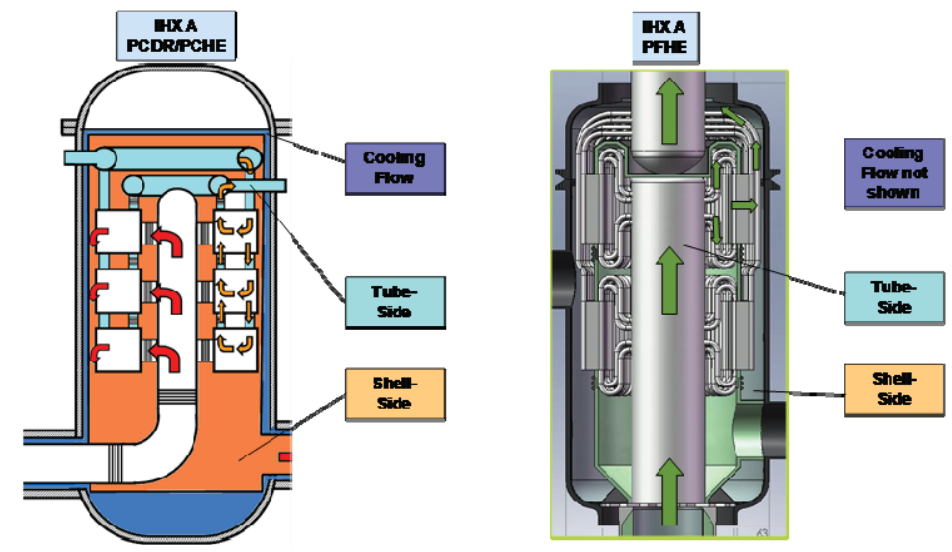

Figure 3. Advanced heat exchanger designs.

- Demonstrate the performance of advanced steam generator designs (see Figure 4) at scale in integrated subsystem tests to confirm thermal hydraulic performance, flow stability and controllability of feed water and steam flows, understand limits on conditions affecting flow induced vibration of tubing, etc.

- Confirm performance, stability, transient response, controllability and interfaces of the gas circulators (see Figure 5) under normal and abnormal operating conditions in integrated subsystem tests with the heat exchange components such as heat exchanger, steam generator, valves when installed, gas ducts. A specific area of interest is the stability and performance of parallel circulator operation, motor cooling performance, seal performance, etc., at scale.

- Confirm the flow regimes, performance and critical interface configurations at the core hot gas outlet plenum to hot duct interface, the hot duct itself and IHX or Steam Generator hot gas and cold gas interfaces as shown in Figure 6.

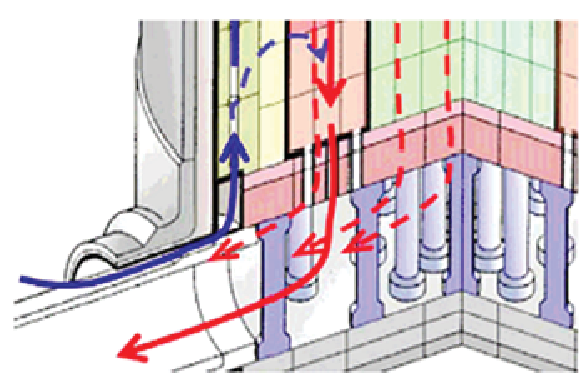

Figure 6. Reactor pressure vessel interface.

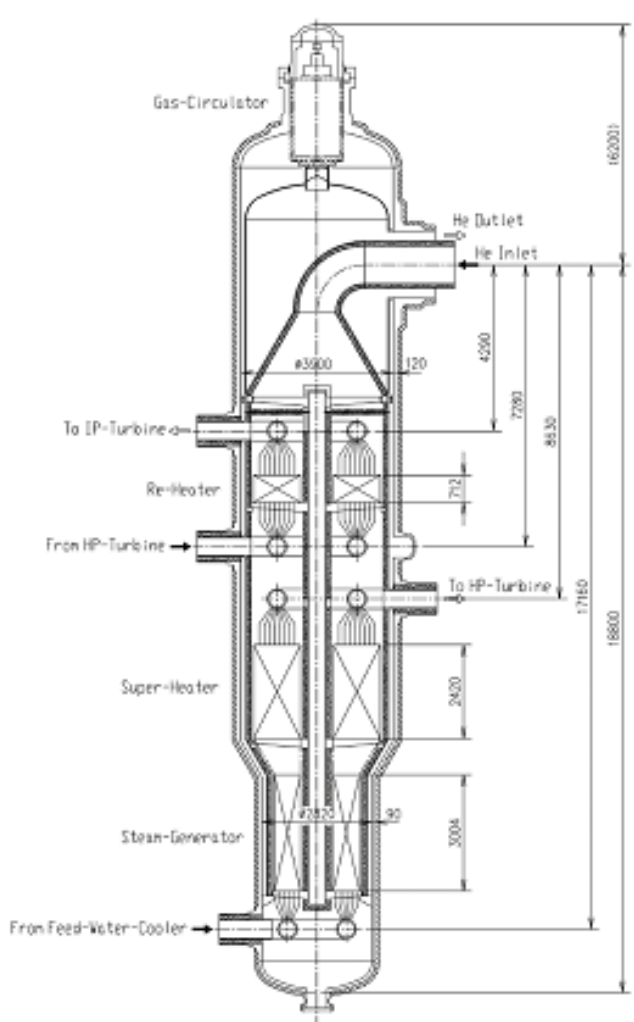

Figure 4. Illustration of an advanced steam generator design.

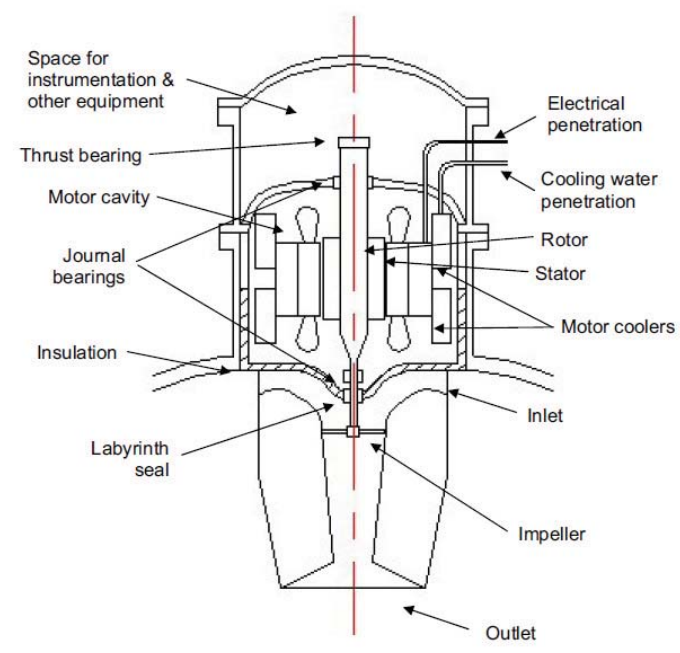

Figure 5. Illustration of a gas circulator.

- Confirm performance of advanced instrumentation and viability of interfaces with plant components, (e.g., instruments for measurement of high temperatures, gas species, pressures and gas flow rates, flux monitors at normal and abnormal operating conditions). 
- Demonstrate hydrogen production processes at temperature and pressure and commercial module scale, (e.g., high temperature electrolysis, sulfur-iodine and hybrid-sulfur processes) in integrated subsystem tests with commercial scale components, (e.g., heat exchangers, steam generators, ducting, piping).

- Confirm the performance of control systems in integrated scale testing such as secondary and primary gas loops as shown in Figure 7 with an IHX under rapid transient conditions such as caused by a trip of the secondary circulator, steam generator dump system performance under high moisture detection conditions in the primary loop indicative of a potential tube leak.

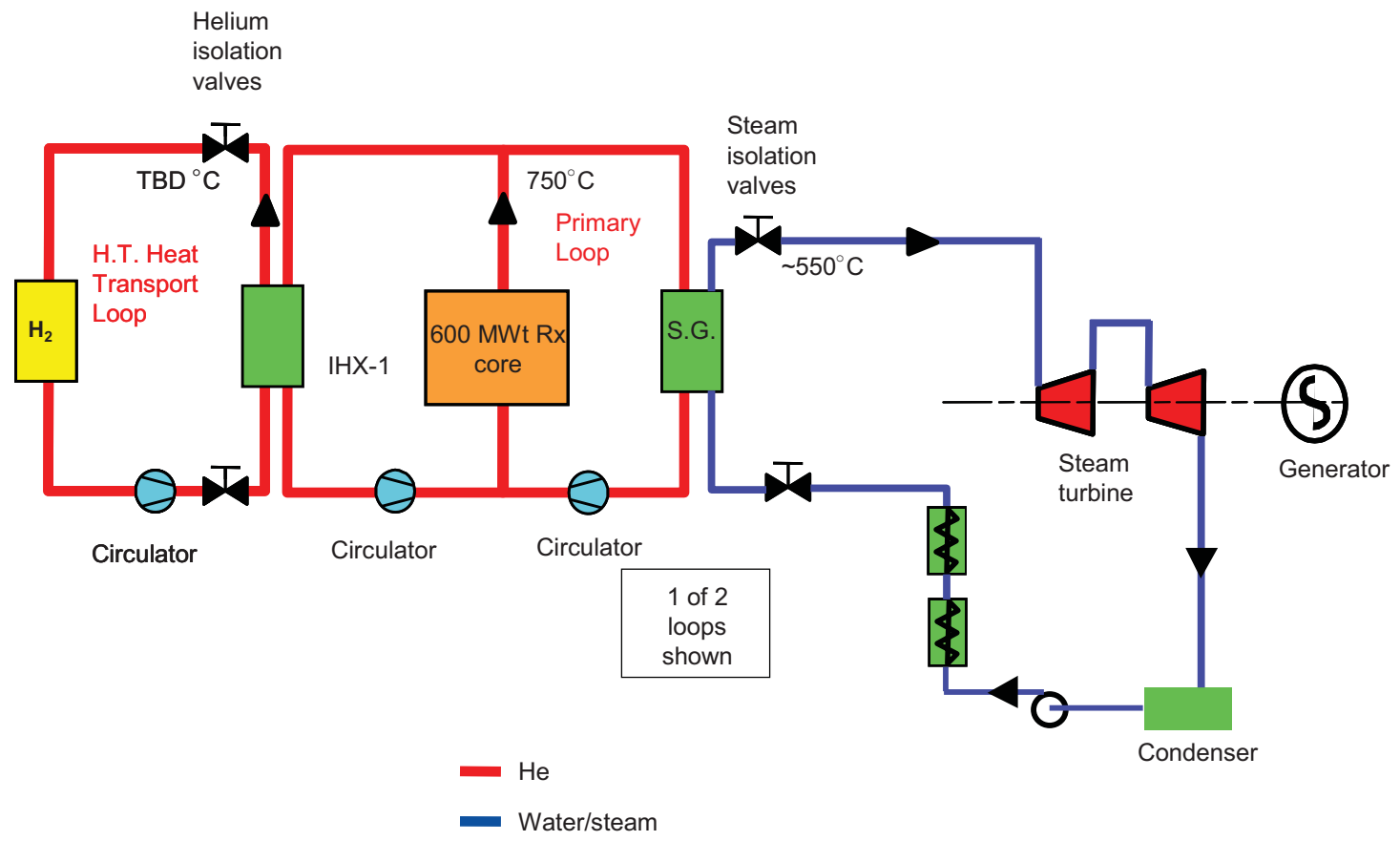

Figure 7. Illustration of control systems in secondary and primary gas loops.

- Confirm proper operation of contaminated gas cleanup loop.

- Develop and demonstrate inspection and test procedures that will be used for construction inspections and preliminary testing, hot startup and commissioning, and in-service inspections on primary and secondary components such as heat exchangers, steam generators, hot gas ducting, valves, circulators.

Large-scale is required to ensure that the developmental component and system designs are ready for installation and operation in NGNP. The NGNP design extends technologies in several areas. It will employ gas circulators two to three times larger (11 MWe to $16 \mathrm{MWe})$ than those currently in service (up to $5 \mathrm{Mwe}$ ). It will use an indirect heat transfer/transport system with developmental IHX designs, (e.g., compact printed circuit, plate-fin, or welded plate designs), spiral tube heat exchangers and steam generators that are significant extensions of the state-of-the-art, and developmental isolation and relief valves. Significant design development and testing is required of these components to ensure successful operation in NGNP.

The three candidate hydrogen generation processes are currently in laboratory scale development (high temperature electrolysis, hybrid sulfur, and sulfur-iodine). A large-scale component test capability is required to perform full scale engineering tests of these process modules prior to installation in NGNP. It is not practical to use the NGNP for this purpose. NGNP will be used to demonstrate production at commercial scale (multiple modules). 
Tables A-1, A-2, and A-3 in Appendix A show the recommended locations for each of the test plans. The majority of the locations recommended for small-scale testing are the supplier facilities. The Supplier Teams include a number of potential suppliers of some of the components, (e.g., heat exchangers, steam generators, turbine generators, valves). These suppliers have been effective in supporting the development of testing requirements and assessing their capabilities and the capabilities of others in providing the testing facilities. As noted in the recommended location for the majority of the large-scale prototypes (TRL 7 and 8), testing is recommended for a component test capability. In summary, the design work performed to date for the NGNP has specified a considerable amount of testing to advance the technology readiness of the critical SSCs to the level necessary to have sufficient confidence in their performance and reliability to install in the NGNP. A large-scale-testing capability is required to meet these needs.

\subsubsection{Risk Assessment}

An objective of developing the TDRMs, which include the test plans, for the critical NGNP SSCs is to identify and address the areas that have significant risk to completing the NGNP Project within budget and on schedule. A further objective is to provide confidence that when the SSC is installed its reliability and performance will support reliable and efficient operation of the plant. Accordingly, risk assessments have been made for the critical SSCs addressing where such risks could affect Project cost, schedule, performance, and reliability and how the test programs and large-scale testing in particular can mitigate those risks. The risks fall into the following generally applicable areas, which identifies the testing addressed in each area:

- Testing at every stage of design development reduces the risk of encountering defects in the design and therefore the significant cost, schedule, and performance impacts if those defects are discovered late in the design process or during plant operation.

As noted in the TDRMs and test plans for NGNP, each phase of testing has a role in developing and proving the design of SSCs, including the analytic models that are used to predict the performance of the SSCs, individually and as part of an integrated system, for normal operating conditions (e.g., startup, plant power maneuvering, load demand variations) and abnormal conditions (e.g., component or plant trips, component failures). The validation of the models are important to ensuring that they are effective in confirming the design meets performance requirements and, where applicable, in performing the safety analyses in support of the licensing process (e.g., for nuclear safety related SSCs). The use of testing at each phase of the design process to validate the design and models can identify defects early in the design process. Studies and industry experience, discussed later, show that early detection of defects results in significantly lower impact on project total cost over identifying them later in the process. This is particularly true if the defect is discovered during plant operation. The TDRMs and test plans show that the final stage of testing, which has been emphasized herein at full scale or near full scale, is the final validation of the design in several respects (as discussed in the following). This step is critical to ensuring the performance and reliability of the SSC prior to installation in the plant.

- Large-scale prototype testing proves the performance of plant scale components prior to installation.

Subscale testing applied in the early and mid stages of the design process provides progressive validation of the design concepts. The final stage of large-scale prototype testing provides assurance of the component's performance at plant scale (e.g., heat exchanger effectiveness, valve leak tightness, steam generator stability margins, hot duct insulation effectiveness, gas circulator stability). This reduces the risk of poor component performance when installed in the plant.

- Large-scale prototype testing addresses the risk that there will not be a viable supplier for the SSC.

The developmental aspects of many of the NGNP components (e.g., advanced heat exchangers, steam generators, valves, instrumentation) requires not only development and proof of the design but also 
the development of suppliers for the components. This also includes supply of qualified material, particularly for components that will be exposed to the high temperatures expected during NGNP operation. A number of the NGNP Project DDNs address material qualification and supply issues. The experience in working with the material and component suppliers in producing the components at full or near full scale for prototype testing mitigates this risk and promotes assurance of material and component supply for NGNP and for subsequent commercial application of the technology.

- Large-scale prototype test capability in a stand-alone DOE-owned facility becomes an important tool for a successful supplier development program.

Few suppliers have proven to be viable in supplying HTGR components for yet-to-be-developed technologies. An excellent incentive in the support of supplier development would be to offer largescale component testing to suppliers for only the cost of utilities, encouraging lower risk development of competitive component suppliers. This will ultimately promote the development of industry and uniformly develop performance criteria for all suppliers interested in competing to provide HTGR critical SSCs.

- Large-scale prototype testing mitigates the risk of encountering problems in fabricating the component that result in procurement and construction delays.

The heat exchangers, steam generators, hot gas ducting, and some reactor internals are large, complex, developmental components. Their performance and configuration concepts will be proved through subscale and modular testing as their designs progress. The provision of full- or near-fullscale prototypes will help identify any fabricability issues at the plant scale to reduce the risk that problems will be encountered during procurement for the plant or during plant construction. Examples of such problems that were encountered in actual projects are discussed below in the section on industry experience.

- Integrated large-scale prototype testing of subsystems addresses the risk of incompatible interfaces, unacceptable interactions among components, or ineffective control systems that result in delays in construction, cold and hot startup testing and commissioning of the plant, or poor performance during operation. Assessing dynamic response in an integrated system will mitigate the risk of unacceptable steady state and transient performance early on.

The NGNP TDRMs and test plans identify requirements for integrated large-scale testing of critical subsystems to prove the effectiveness of systems and controls in meeting plant performance requirements. Such testing in a facility separate from the plant can identify design problems prior to construction, startup testing, and installation in the plant. In the extreme, this avoids using the plant as the test bed and attempting to diagnose and resolve problems in the commercial and, in the case of nuclear technologies, heavily regulated environment. Industry experience, as discussed below, has shown the consequence of using the plant as the test bed.

- The installation of large-scale prototype components in a test facility provides the opportunity to use hands-on experience with these components in the development of inspections and tests that will be used in plant construction, hot and cold startup testing, and in-service-inspections during operation. This reduces the risk of encountering problems with these inspection and test procedures during construction and commissioning resulting in delays or during operation causing extension of outages.

\subsubsection{Industry Experience}

Numerous project management guidelines and principles emphasize the need to ensure that technology is well understood before starting construction and/or operation of major developmental projects. Industry experience demonstrates the consequences of not following these principles. The U.S. Government Accountability Office (GAO) has performed several assessments of DOE projects that have had significant cost and schedule overruns for this reason. 
The following excerpts are taken from two GAO accepted reports:

- A March 2007 GAO review of DOE projects ${ }^{14}$ had the following general observations:

"Nine of the 12 DOE major projects we reviewed have exceeded their original cost estimates and/or experienced schedule delays, principally because of ineffective DOE project oversight and poor contractor management, according to independent studies we reviewed and interviews we conducted with DOE and contractor project officials. Specifically, 8 of the 12 projects experienced cost increases ranging from $\$ 79.0$ million to $\$ 7.9$ billion, and 9 of the 12 projects are behind schedule by 9 months to more than 11 years. Major factors cited for these cost increases and delays included the following:

Ineffective DOE project oversight. For all 9 projects experiencing cost increases or schedule delays, poor DOE oversight was a key contributing factor. Project oversight problems included inadequate systems for measuring contractor performance, approval of construction activities before final designs were sufficiently complete, ineffective project reviews, [emphasis added] and insufficient DOE staffing and project management experience.

Poor contractor management. Eight of the 9 major projects experienced cost increases and/or schedule delays, in part because contractors did not effectively manage the development and integration of the technology used in the projects, including not accurately anticipating the cost and time that would be required to carry out the highly complex tasks involved. For example, the National Ignition Facility has had over \$1 billion in cost increases and years of schedule delays owing in part to technology integration problems, according to the DOE project director."

- The review had the following comments on specific DOE projects:

"DOE's experience in the predecessor project to the Salt Waste Processing Facility - the In-Tank Precipitation (ITP) project process - at the Savannah River Site illustrates the potential consequences of proceeding with technology that is not sufficiently ready [emphasis added]. As we reported in 2000, the ITP project was selected in 1983 as the preferred method for separating highly radioactive material from 34 million gallons of liquid stored at the Savannah River site. ... In 1985, DOE estimated that it would take about 3 years and $\$ 32$ million to construct the ITP facility. After a number of delays, the ITP facility was constructed and began start-up operations in 1995, which were halted because of safety concerns about the amount of benzene that the facility generated. In 1998, after about a decade of delays and costs of almost $\$ 500$ million, DOE suspended the project because it did not work as safely and efficiently as designed. This suspension put an effective remedy for treating high-level waste at the Savannah River Site years behind schedule."

- The review had the following observations on the DOE-Waste Treatment and Immobilization Plant Project in Hanford, WA:

“... DOE's approval of construction activities before final designs were sufficiently complete has contributed significantly to project cost growth and schedule delays. As we have previously reported, the accelerated fast-track, design-build approach used for the Waste Treatment and Immobilization Plant, a highly complex first-of-a-kind nuclear facility, resulted in significant cost increases and schedule delays.

....DOE's experience with the Waste Treatment and Immobilization Plant is a case in point. Specifically, technology known as "pulse jet mixers" were used in the design of a 
subsystem intended to prepare radioactive material for processing. However, this technology had not been used previously in this application, and it did not work in tests as expected, even after construction had already begun. Consequently, DOE incurred about $\$ 225$ million in redesign costs and over 1 year in schedule delays, according to the DOE project director."

- In testimony presented to the Task Force on Natural Resources and the Environment in July 2000, ${ }^{15}$ the GAO representative made the following observations:

"A number of management and oversight problems caused DOE and Westinghouse Savannah River Corporation (Westinghouse), DOE's contractor, to spend almost a half billion dollars and to take about a decade before deciding that the ITP process would not work safely and efficiently as designed. For example, in 1993, a technical review team reported that the contractor tended to react to problems after they occurred, rather than working to prevent them in the first place. The team also found that DOE lacked the necessary personnel for adequate oversight. Moreover, DOE and the contractor encountered delays in starting up the ITP facility because they had begun construction before the design of the process was completed. DOE and the contractor also did not adequately understand the cause of the technical problems-such as a lack of understanding of the chemistry involved in the ITP process--that made the process unworkable. ... the contractor appears to be focusing on an engineering solution on the basis of untested assumptions."

- The March 2007 GAO review of DOE projects ${ }^{15}$ made the following recommendation to improve DOE's understanding of the technological readiness of developmental components and systems:

"To effectively assess technology readiness, NASA pioneered and DOD has adopted a process for measuring and communicating technology readiness for first-of-a-kind technology applications. This process uses a nine-point scale for assessing TRLs. Using this scale, a technology would receive a higher TRL value (e.g., TRL 7) if it has been successfully demonstrated in an operational environment, compared with a technology that has been demonstrated only in a laboratory test (e.g., TRL 4). Several DOE project directors we spoke with agreed that a consistent, systematic method for assessing technology readiness would help standardize terminology, make technology assessments more transparent, and help improve communication among project stakeholders before they make critical project decisions.

To improve oversight and decision making for DOE's major construction projects, we are recommending that the Secretary of Energy evaluate and consider adopting a disciplined and consistent approach to assessing TRLs for projects with critical technologies."

As noted in the prior sections of this report the NGNP Project has undertaken a comprehensive Technology Development Roadmap program with emphasis on establishing the current technology readiness of the critical SSCs and the work necessary to advance the technology readiness to the level necessary to ensure reliable and required performance of the SSC prior to installation in the plant. This work includes significant amounts of testing at every phase of technology advancement and design development. As noted previously, large-scale testing is the ultimate stage at which final assurance is obtained on the efficacy of the design before installation in the plant.

The basis for early detection of defects in the design process is shown in Figure 8 (excerpted from the Electric Boat presentation to NGNP ${ }^{16}$ ). The figure shows that design decisions made early in the process have major impact on the total project cost (e.g., decisions in conceptual design account for $70 \%$ of the 
committed cost of the project). The red line shows the consequence of late detection of defects in the design. The cost of not correcting defects in the conceptual design phase is 100 times more in the development phase and 1,000 times more in the production phase. Clearly, successful execution of the TDRM process, including testing, is critical to maintaining the project on schedule and within budget.

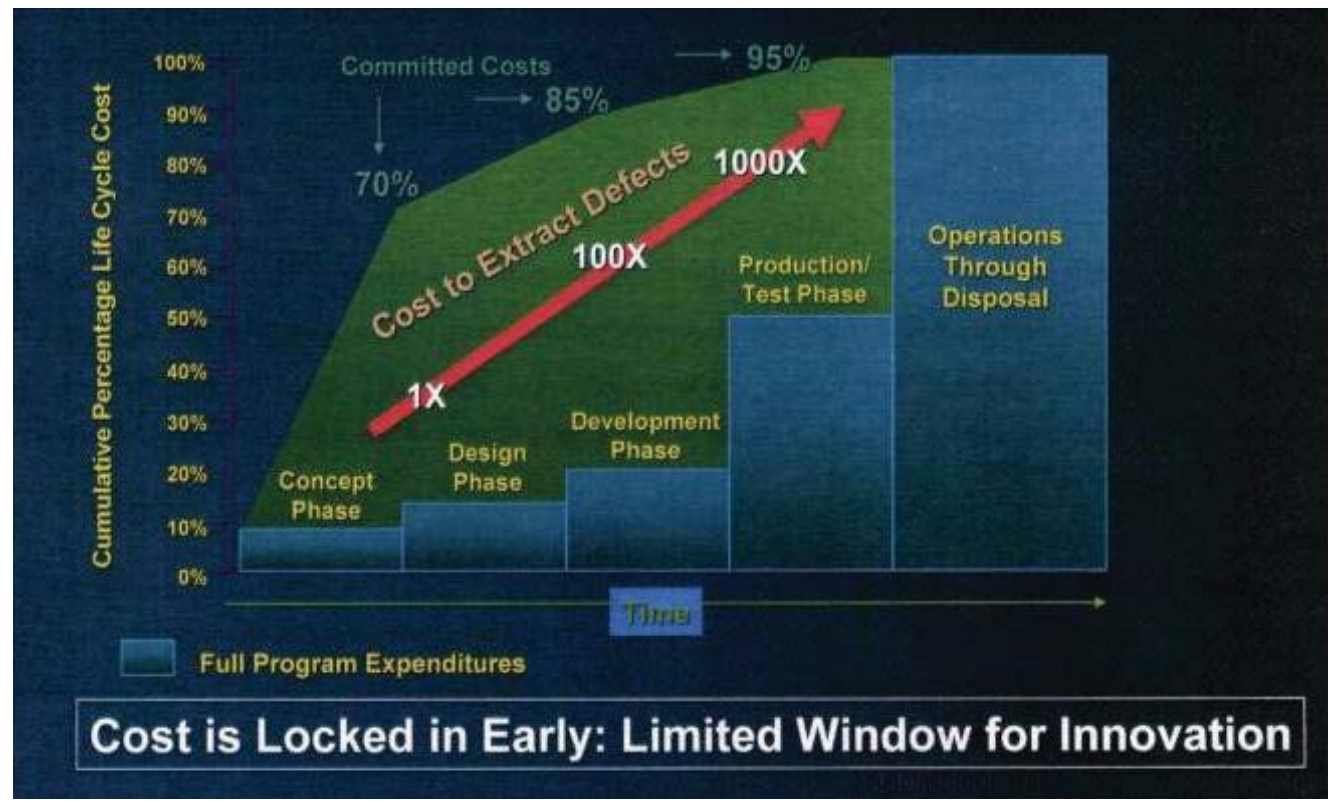

Figure 8. Innovation impact on program cost.

A difficult experience with gas reactor technology in the Fort St. Vrain plant ${ }^{17}$ is an example of how a supporting component that was not fully tested prior to installation can have a significant impact on the plant performance. In this case the primary gas circulators were driven by steam turbines. The seals on the turbine drives leaked into the primary coolant system causing frequent moisture ingress events that required plant shutdown and extended outages for primary system cleanup. These problems contributed to the early decommissioning, decontamination, and demolition of the plant. This experience also led to the use of electric driven gas circulators located outside of the core in the NGNP design.

Finally, an example of the benefits of full-scale testing in ensuring the performance of SSCs prior to installation is the experience with the fullscale mockup facilities in INL Bldg 765 shown in Figure 9. The hookup tests out the instrumentation and controls of SSCs prior to installation in the HFEF hot cells as part of the Hot Cell Equipment Design Risk Management program. This program has been critical to ensuring that the equipment has the required performance and reliability and that the operators have the required access and controls to perform required functions before the equipment is inserted in the hot cell where access and ability to do hands-on work is very limited. This is a condition that is similar to and has the same benefits of testing on actual full-scale components as the NGNP Project.

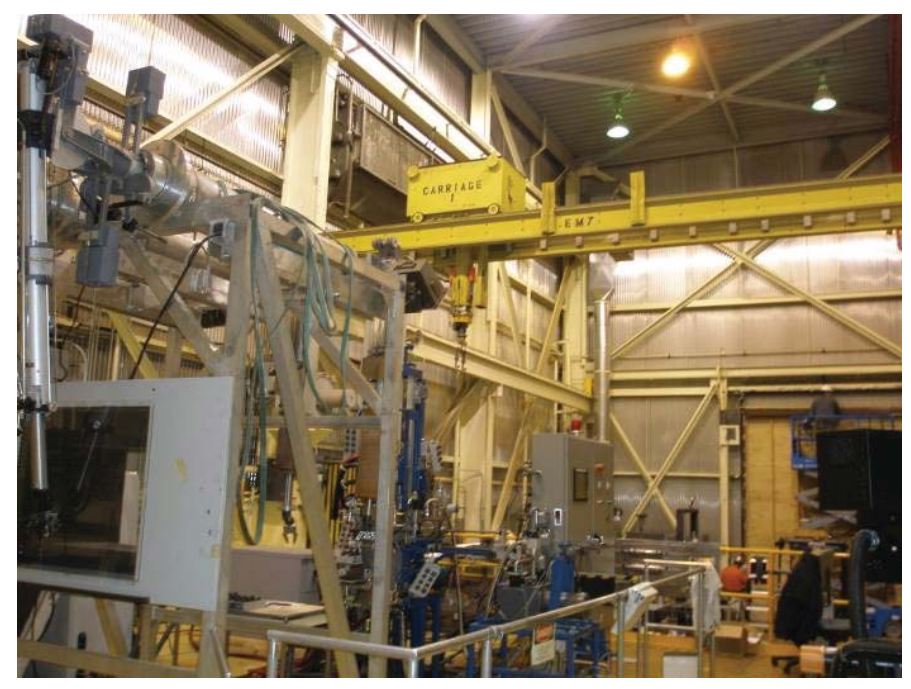

Figure 9. Full-scale mockup facilities in INL Bldg 765 
Table 1. Summary of worldwide existing and planned fluid flow test facilities.

Legend: Decommissioned Operational Planned or in construction

\begin{tabular}{|c|c|c|c|c|c|c|c|}
\hline Facility & $\begin{array}{l}\text { Organization } \\
\text { (Country) }\end{array}$ & $\begin{array}{l}\text { Heating } \\
\text { Power } \\
\text { (MW) }\end{array}$ & $\begin{array}{c}\text { Flow } \\
\text { Rate } \\
(\mathrm{kg} / \mathrm{sec})\end{array}$ & $\begin{array}{c}\text { Pressure } \\
(\mathrm{MPa})\end{array}$ & $\begin{array}{l}\operatorname{Tmax} \\
\left({ }^{\circ} \mathrm{C}\right)\end{array}$ & $\begin{array}{l}\text { Availabilityl } \\
\text { Applicability }\end{array}$ & Comment \\
\hline $\begin{array}{l}\text { Minimum } \\
\text { facility } \\
\text { requirements }\end{array}$ & & $\geq 30$ & 20 & 9 & 950 & Needed & $\begin{array}{l}\text { These are requirements based on the } \\
\text { current NGNP project schedule and the } \\
\text { required number of test identified to } \\
\text { date to be performed in parallel. }\end{array}$ \\
\hline EVO (Turbine) & Germany & $\begin{array}{l}120 \\
M^{*}\end{array}$ & $\begin{array}{l}80 \\
M\end{array}$ & $\begin{array}{c}3 \\
\mathrm{DM}^{* *}\end{array}$ & $\begin{array}{l}750 \\
\mathrm{DM}\end{array}$ & Dismantled & \\
\hline HHV (Turbine) & Germany & $\begin{array}{c}100 \\
M\end{array}$ & $\begin{array}{c}200 \\
M\end{array}$ & $\begin{array}{c}5 \\
\mathrm{DM}\end{array}$ & $\begin{array}{l}850 \\
\mathrm{DM}\end{array}$ & Dismantled & \\
\hline $\begin{array}{l}\text { CT-1383 (Main } \\
\text { Circulator) }\end{array}$ & $\begin{array}{l}\text { OKBM } \\
\text { (Russia) }\end{array}$ & $\begin{array}{c}\text { Not } \\
\text { available }\end{array}$ & $\begin{array}{l}95 \\
\mathrm{M}\end{array}$ & $\begin{array}{l}4.9 \\
\mathrm{DM}\end{array}$ & $\begin{array}{l}345 \\
\mathrm{DM}\end{array}$ & $\begin{array}{l}\text { Dismantled/prolonged } \\
\text { storage }\end{array}$ & \\
\hline KVK Loop & $\begin{array}{l}\text { AREVA } \\
\text { (Germany) }\end{array}$ & $\begin{array}{l}10.0 \\
\mathrm{DM}\end{array}$ & $\begin{array}{c}4 \\
\mathrm{DM}\end{array}$ & $\begin{array}{c}4 \\
\mathrm{DM}\end{array}$ & $\begin{array}{c}950 \\
M\end{array}$ & Dismantled. & $\begin{array}{l}\text { Operated for } 13,000 \text { hours, } 7,750 \text { at } \\
900^{\circ} \mathrm{C} 1981 \text { to } 1986 \text {. }\end{array}$ \\
\hline CT-1312 & $\begin{array}{l}\text { OKBM } \\
\text { (Russia) }\end{array}$ & $\begin{array}{c}15 \\
\text { DM }\end{array}$ & $\begin{array}{c}4 \\
\mathrm{DM}\end{array}$ & $\begin{array}{c}5 \\
\mathrm{DM}\end{array}$ & $\begin{array}{c}965 \\
M\end{array}$ & $\begin{array}{l}\text { Dismantled/prolonged } \\
\text { storage }\end{array}$ & $\begin{array}{l}\text { Test of intermediate heat exchangers } \\
\text { and steam generators. }\end{array}$ \\
\hline HENDEL & JAEA (Japan) & $\begin{array}{c}10 \\
\text { DM }\end{array}$ & $\begin{array}{c}4 \\
\text { DM }\end{array}$ & $\begin{array}{c}4 \\
\mathrm{DM}\end{array}$ & $\begin{array}{c}950 \\
M\end{array}$ & Dismantled. & \\
\hline HTTF HTTU & South Africa & $\begin{array}{l}0.5 \\
\mathrm{DM}\end{array}$ & $\begin{array}{l}0.5 \\
\mathrm{DM}\end{array}$ & $\begin{array}{l}10 \\
M\end{array}$ & $\begin{array}{c}1,600 \\
M\end{array}$ & $\begin{array}{l}\text { Unavailable until } 2012 \\
\text { for currently scheduled } \\
\text { tests. Specifically } \\
\text { designed to test DPP } \\
\text { Systems and } \\
\text { components }\end{array}$ & $\begin{array}{l}\text { Insufficient thermal power and flow rate } \\
\text { for engineering-scale test of NGNP } \\
\text { Project components. Major upgrade } \\
\text { needed to achieve } 30 \mathrm{MW} \text { thermal } \\
\text { power and } 20 \mathrm{~kg} / \mathrm{sec} \text { flow rate. }\end{array}$ \\
\hline HTTF HPTU & South Africa & $\begin{array}{l}0.1 \\
\text { DM }\end{array}$ & $\begin{array}{l}2.8 \\
\mathrm{DM}\end{array}$ & $\begin{array}{c}5 \\
\mathrm{DM}\end{array}$ & $\begin{array}{l}35 \\
\mathrm{DM}\end{array}$ & $\begin{array}{l}\text { Not applicable } \\
\text { (specifically designed } \\
\text { to test DPP Systems } \\
\text { and components) }\end{array}$ & $\begin{array}{l}\text { Test fluid is nitrogen .System designed } \\
\text { for high pressure, low-temperature } \\
\left(75^{\circ} \mathrm{C}\right) \text { testing. Major modification } \\
\text { required to support testing of NGNP } \\
\text { Project components at } 30 \mathrm{MW} \text { thermal } \\
\text { power, } 20 \mathrm{~kg} / \mathrm{sec} \text { flow rate, } 9 \mathrm{MPa} \\
\text { pressure, and } 950^{\circ} \mathrm{C} \text { max temperature. }\end{array}$ \\
\hline HTF & $\begin{array}{l}\text { Pelindaba } \\
\text { (South Africa) }\end{array}$ & $\begin{array}{l}1.0 \\
\mathrm{DM}\end{array}$ & $\begin{array}{l}0.5 \\
\mathrm{DM}\end{array}$ & $\begin{array}{c}6 \\
\mathrm{DM}\end{array}$ & $\begin{array}{c}1,000 \\
M\end{array}$ & $\begin{array}{l}\text { Specifically designed to } \\
\text { test DPP Fuel Handling } \\
\text { System }\end{array}$ & $\begin{array}{l}\text { Major modification required to be useful } \\
\text { to the NGNP Test Program at } 30 \mathrm{MW} \\
\text { thermal power, } 20 \mathrm{~kg} / \mathrm{sec} \text { flow rate and } \\
9 \mathrm{MPa} \text { pressure. Would be useful in all } \\
\text { PBMR Fuel Handling System } \\
\text { development activities. }\end{array}$ \\
\hline HELITE Loop & $\begin{array}{l}\text { CEA } \\
\text { Cadarache } \\
\text { (France) }\end{array}$ & $\begin{array}{l}1.2 \\
\mathrm{DM}\end{array}$ & $\begin{array}{l}0.4 \\
\text { DM }\end{array}$ & $\begin{array}{c}8 \\
\mathrm{DM}\end{array}$ & $\begin{array}{c}950 \\
M\end{array}$ & See comment & $\begin{array}{l}\text { Design is complete; project is on hold } \\
\text { waiting funding. Thermal power } \\
\text { insufficient for engineering-scale tests } \\
\text { of NGNP Project components. }\end{array}$ \\
\hline HELOKA & $\begin{array}{l}\text { FZK, Karlsruhe } \\
\text { (Germany) }\end{array}$ & $\begin{array}{l}3-8 \\
\text { DM }\end{array}$ & $\begin{array}{c}1.8-5.5 \\
\text { DM }\end{array}$ & $\begin{array}{l}10 \\
M\end{array}$ & $\begin{array}{l}700 \\
\mathrm{DM}\end{array}$ & See comment & $\begin{array}{l}\text { In development, operational in } 2009 . \\
\text { Insufficient temperature capability for } \\
\text { engineering-scale tests of NGNP } \\
\text { Project components. }\end{array}$ \\
\hline AECL - SNL & United States & $\begin{array}{c}0.5-1 \\
\text { DM }\end{array}$ & $\begin{array}{c}\text { Not } \\
\text { available }\end{array}$ & $\begin{array}{c}\text { Not } \\
\text { available }\end{array}$ & $\begin{array}{c}\text { Not } \\
\text { available }\end{array}$ & See comment & $\begin{array}{l}\text { Configured for Brayton cycle critical } \\
\mathrm{CO}_{2} \text { fast gas reactor systems. Could be } \\
\text { retrofit for helium gas-cooled thermal } \\
\text { reactor work. Insufficient thermal power } \\
\text { for engineering-scale test of NGNP } \\
\text { Project components. }\end{array}$ \\
\hline
\end{tabular}




\subsection{Existing Test Loop Capabilities}

On the basis of the critical SSC test plans as discussed in Section 3.4.1 of this paper, studies were performed by the reactor suppliers of the capabilities of existing test loops in the U.S., Europe, South Africa and Russia. These studies concluded that these facilities either do not have the required capabilities or are not suitable for NGNP testing. The larger ones $(=10 \mathrm{MWt})$ are no longer operating and have been dismantled. The smaller ones do not have the combined flow, pressure and temperature capabilities and are designed for very specialized and focused purposes, (e.g., the Helium Test Facility in South Africa). In summary, only two such facilities that may have partial capability exist in the world and they are both offshore and dedicated to the development of technologies in those countries. In addition to these studies, an independent assessment of the available test facilities was conducted ${ }^{18}$ and concluded the following.

Alternative high temperature test loops have been identified with similar capabilities to the component test capability but are not suitable for lifecycle support of the NGNP.

- Existing loops give scheduling priority to their country/organization of origin.

- Most loops are too small for full-scale NGNP component testing.

- Additional independent facilities were identified for component-level and process-level testing. Due to limitations listed below, these facilities do not supplant the need for the proposed component test capability.

- Component-level test facilities do not have access to high temperature and high pressure helium.

- Component-level test facilities are not sufficiently large to perform full-scale testing.

- Test facilities with NGNP related process experience (i.e., SI or Hybrid SI Loops) do not have the size or power infrastructure for full-scale testing.

\subsection{Considered Testing Alternatives}

The following provides various alternatives for completing the large scale integrated testing necessary to validate the interfaces and performance of critical systems and components prior to installation in the plant. These include:

1. Do Nothing - no large-scale testing of NGNP critical SSCs except during cold start-up in the plant.

2. Distribute the testing requirements to the component and system vendors as part of the specifications for procurement.

3. Modify existing facilities (mostly overseas) to support NGNP large-scale test needs.

4. Construct a stand-alone facility to house and operate test loops designed to meet NGNP large-scale testing needs.

\subsection{Additional Considerations for Conducting the Alternatives Analysis}

Evaluation of the above alternatives and any others not yet identified for establishment of the component test capability will be developed following the approval of this Mission Needs (CD-0) and submitted as part of the CD-1 approval request.

The initial use of this capability will be in technology development support of the NGNP Project heat transfer and transport system components, reactor pressure vessel/internals, and high temperature instrumentation and controls. It also will provide a means for operator/maintenance training, offline 
trouble shooting of component and system problems during the operation of NGNP, and for technology development of programs and processes that will support growing nuclear reactor technology development, including integration with industrial processes requiring high temperature heat sources.

Because the initial use of this capability would directly support the NGNP Project, the NGNP Project development schedule has been used to create an integrated schedule (see Figure 1) for initial implementation of this capability. From the TDRMs developed for critical SSCs of the NGNP, an overall schedule and plan will be developed to support taking all critical SSCs to a TRL of 8, corresponding to a maturity level appropriate to an attractive commercialization offer. As critical SSCs are completed to help bring the NGNP on line, other activities can then be scheduled to support nuclear reactor development.

Although the required large scale testing capabilities are anchored by the needs of the NGNP project, the testing needs of other international programs requiring high temperature process heat could potentially benefit from such a capability. These benefits are in the areas of advanced research and development to assist in commercial deployment of energy technologies and should be considered in the life cycle analysis of any proposed capability. These benefits are discussed in the following:

\subsubsection{Fusion Support Capability}

Fusion blanket technologies share much in common with fission energy conversion technologies. As a result, a component test capability for HTGRs would be of benefit to fusion. Two classes of fusion blankets are receiving the greatest attention worldwide: helium-cooled blankets with a variety of lithium ceramics to breed tritium, and a lithium-lead-cooled blankets. Both of these systems operate at high temperature. The helium-cooled blanket systems want to achieve outlet temperatures ranging from 750 to $950^{\circ} \mathrm{C}$. The lithium-lead-cooled blankets want to achieve outlet temperatures between 500 and $700^{\circ} \mathrm{C}$, depending on the structural material of choice. The key high temperature components that need to be qualified for the helium-cooled blanket systems are very similar to those for HTGRs (compressors, valves, and heat exchangers). For the lithium-lead-cooled systems, a lithium-lead test loop is added to the capability, which could be used to study the thermal hydraulic performance of lithiumlead-cooled systems and the associated pumps, valves, and heat exchangers. One additional requirement for the lithium-lead-cooled blanket system would be to test the behavior of the coolant in the presence of a magnetic field where magnetic forces can change the flow and cooling behavior of the liquid metal. Insulators are under development to prevent magnetic penetration into the liquid metal to minimize this effort and the NGNP test capability could be utilized as a test bed to validate the performance of these insulators under a magnetic field and flowing liquid lithium-lead prototypic of a fusion system.

\subsubsection{Hybrid Energy End User}

The development of a large-scale component test capability is also complementary with the objectives of the Battelle Energy Alliance/INL Energy Security Initiative, which includes the Hybrid Energy System development program. This program is undertaking accelerated integration of nuclear power, including the HTGR technology, with broader energy system development such as production of clean burning synthetic transportation fuels derived from coal and biomass. This program takes advantage of the noncarbon-emitting characteristics of nuclear power energy for the production of very low carbon electricity, transportation fuels, and process heat. The objectives of the Hybrid Energy System Program are to develop and demonstrate the overall efficiency, environmental performance, and economic benefit of these systems to the United States. An important element of this program is the HYTEST, which is being developed to advance critically enabling engineering research in the areas of feedstock preparation, heat transfer, fuels and product synthesis, byproduct management, and advanced diagnostics and controls. The HYTEST laboratory will also address component and system integration and dynamics challenges. Many of these component and process level challenges are common with NGNP needs, and the projects will be leveraged to support NGNP test program needs. 


\subsubsection{Other DOE Programs}

In addition to supporting advanced reactor R\&D needs, including those for both HTGRs and Supercritical $\mathrm{CO}_{2}$ cycles, the component test capability may provide complementary support to other DOE programs. Among these are programs and initiatives that are targeting fossil-based energy systems that strive for both higher efficiencies and lower greenhouse gas emissions. Just as in the NGNP Program, advanced fossil energy boilers and steam turbines operating at ultra supercritical conditions require validation of component performance and behavior at temperatures up to $760^{\circ} \mathrm{C}$ or higher. Many of the components required for these fossil systems (pressure vessels, headers, heat exchangers, valves, turbines, etc.) will likely be fabricated using in part, some of the same alloys envisioned for NGNP, including Inconel 617 and Haynes 230. In the event that reactor vendors propose a steam generator be incorporated directly into the primary loop of the NGNP, tube materials equivalent to those suggested for advanced fossil energy systems may be used such as Alloy $800 \mathrm{H}$. Similarly, both the NGNP and fossil programs have complementary needs in the area of corrosion, high temperature material oxidation, and erosion.

Even if the configuration of the test loops currently identified within this capability gap were not to replicate the specific pressures envisioned for some fossil systems (>30 MPa), it may of utility in acquiring valuable data on the performance of components driven by temperature and secondary deformation controlled stresses such as differential thermal expansion in thick sections of the components. As such, valuable information on these loads as well as fabrication and joining practices, in-service inspection, and nondestructive examination that benefit other fossil energy initiatives may be achieved at with the component test capability subject to this report, even at lower operating pressures.

\subsubsection{DOE/NRC Programs}

In addition to supporting DOE R\&D needs, the component test capability may provide complementary support to NRC programs. As noted in U.S. Nuclear Regulatory Commission Long-Term Research: Fiscal Year 2009 Activities: "Test facilities that provide empirical data on the performance of systems constitute an important part of the technical infrastructure supporting regulatory decision making. Separate effects facilities are utilized for activities such as model development and validation, and integral effects facilities are utilized for activities such as assessing overall system performance."19

The U.S. Department of Energy/Nuclear Power Industry Strategic Plan for Light Water Reactor Research and Development ${ }^{20}$ identifies the need for cross-cut monitoring, which would apply to existing light water reactors and advanced reactor designs:

- Technologies to conduct real-time performance monitoring of major nuclear plant components (e.g., reactor coolant pump seals)

- Technologies, criteria, and methods to implement improved online monitoring, including sensors required for high-temperature operation and validation of related data processing/life estimation algorithms, to support operations and maintenance of plant equipment and components

- Advanced inspection techniques for critical plant structures, systems, and components

- Models of and monitoring techniques for environment-related phenomena and environmental variables affecting the rate of material degradation.

As a test platform for integrated testing as well as accelerated effects testing (high temperature conditions), the component test capability may provide a critical ability to demonstrate and validate the development and application of new techniques and instrumentation relating to life management and operational reliability to seek to ensure the ability to deliver safe, reliable plants with a high capacity factor. Specific ways in which the component test capability could be used include as a test platform for diagnostics and prognostic monitoring instrumentation, and to give validation and verification for life 
estimation methodologies, currently being considered for development under programs supporting the DOE-NE Light Water Reactor Sustainability Program ("Life Beyond 60: NRC/DOE Workshop on U.S. Nuclear Power Plant Life Extension Research and Development" initiative) and the NRC Proactive Management of Material Degradation Research Program.

In addition to monitoring technologies, both NRC and DOE programs also have needs in digital instrumentation and controls (I\&C) research that may be addressed in part through development and empirical testing capabilities available through a component test capability. The NRC's current research plan for digital I\&C includes needs for data to be used to establish a regulatory technical basis in the areas of diversity and defense in depth in digital systems for controlling and monitoring nuclear processes; highly integrated control rooms; security aspects of digital systems; and emerging technologies. Technical areas in the DOE Light Water Reactor Sustainability Program research pathway for digital I\&C include advanced instrumentation, information, and control technologies; aging assessment and characterization of systems, structures, and components covered by 10 CFR Part 54 including concrete, cabling, buried piping and new materials; and advanced monitoring, characterization, and predictive performance management of materials. Leveraging capabilities that will be developed for a component test capability applications may provide suitable facilities for research in digital I\&C technologies.

A component test capability can support cross-cutting research of issues affecting both the current licensing basis of light water reactors in some of the areas mentioned when used to augment or accelerate testing in existing facilities, as well as to conduct research into advanced instrumentation, information, and monitoring technologies. 


\section{CONCLUSIONS}

A gap between component test needs and testing capabilities was identified during the development of test plans for first-of-a-kind components and systems for the NGNP. Hence, a mission need exists to fill this testing capability gap to mitigate technology cost and schedule risks.

A need for large-scale testing capability has been shown to be necessary to mitigate project technical, cost, schedule, and performance risks and thereby increase confidence in the success of the NGNP Project. Significant test requirements have been identified in design work performed to date for the Gen-IV NGNP Project to ensure the performance and reliability of developmental and critical SSCs for this advanced high temperature gas-cooled graphite moderated nuclear reactor technology. The more critical components and systems include gas circulators, heat exchangers, high temperature steam generators, valves, hydrogen production processes, and instrumentation and controls. The ability to test these critical SSCs at full or near full scale has the benefits of:

- Validating the design(s)

- Confirming the availability of suppliers and materials, fabricability of the components and systems, and viability of interfaces and performance

- Providing an effective means for developing and proving prestartup and operational inspection and test processes.

The required capabilities for this testing have been described and some alternatives for providing these capabilities for the NGNP Project have been roughly formulated. Even though the areas of required large-scale testing identified to date are significant, because the NGNP Project has only initiated conceptual design, it is judged that additional large-scale testing needs will be identified as the design progresses. Accordingly, it is essential that the testing capability be flexible to adapt to evolving needs.

Studies of the need for large-scale-component testing have identified that a large-scale component test capability has other benefits in supporting the development of advanced nuclear reactor technologies. ${ }^{21}$ These include:

- Verification and validation of methods/codes to support licensing and future commercial applications (thermal, hydraulic, transients, etc.)

- Confirming materials performance at greater than laboratory scale such as metallic and ceramic

- Developing and proving fluid inventory and quality control systems such as contamination cleanup and control

- Assessing control room human factors

- Assessing dynamic response of integrated components and systems

- Operational procedure development and qualification training

- Operational problem/trouble shooting

- High temperature application interfaces and engineering-scale testing and qualifications such as hydrogen production, coal to liquids, steam generators for Alberta Oil Sands application, etc.

- Maintenance and repair program and process development

- Component replacement program and process development

Although the specific test requirements discussed herein have been focused on the NGNP Project, the critical SSCs are characteristic of developmental requirements for the broad scope of the Gen-IV 
advanced nuclear reactor technologies. Each of these technologies need to address the development of components and systems with capability to transfer high temperature energy from the reactor to the energy conversion process using their specific fluids and reactor configurations such as molten salt, molten lead, supercritical steam, and sodium. As identified in the NGNP Project, the specific developmental components will include prime movers (e.g., pumps), heat exchangers, valves, instrumentation, and controls. Accordingly, it is judged that the development of a large-scale-testing capability to support the NGNP project will benefit the full range of Gen-IV advanced nuclear reactor technology developments.

The discussion on industry experience and principles of effective project management summarized the benefits of testing throughout the design development process and the importance of large-scale prototype testing in mitigating project risks to schedule and cost overruns and operational performance deficiencies. Examples of problems encountered in major DOE first-of-a-kind projects that did not take advantage of all testing benefits are pervasive and significant. This experience provides further support for ensuring that large-scale component test capability is available for the NGNP Project and continuing development of the full range of Gen-IV advanced nuclear reactor technologies.

Although the large-scale component test capability is essential in the short term for expedient development and application of the advanced nuclear reactor technologies, it has an equally important long-term role in supporting the continuing development of the full potential of these technologies by supporting advances in their capabilities and application to wider ranges of applications. The NGNP Project is only the beginning of the development of advanced nuclear reactor technologies. Individually and in sum, the development and commercialization of advanced nuclear reactor technologies will introduce significant sustainable resources to the energy supply portfolio of the country. This energy supply has significant potential benefit to the country and the environment in that it does not release greenhouse gases, it uses domestically supplied fuel, and replaces the burning of fossil fuels thereby improving our energy security by reducing our dependence on offshore sources and husbanding our domestic sources of fossil fuels. The Gen-IV and hybrid nuclear programs discussed herein, including NGNP, have only just begun to develop and exploit the benefits of these technologies. A large-scale component test capability that can be accessed by domestic and international supporters and developers of advanced nuclear reactor technology provides an essential resource for ensuring expeditious and continuing development of these important technologies. 


\section{REFERENCES}

1. U.S. Department of Energy Strategic Plan, (www.cfo.doe.gov/strategicplan/docs/2006StrategicPlan.pdf)

2. DOE-NE, Generation IV Energy Systems Ten Year Program Plan, U.S. Department of Energy Office of Nuclear Energy, Science and Technology, September 2007.

3. U.S. DOE Nuclear Energy Research Advisory Committee and the Generation IV International Forum, A Technology Roadmap for Generation IV Nuclear Energy Systems, GIF-002-00, December 2002, p.17; http://gif.inel.gov/roadmap/pdfs/002_a technology_roadmap_for_gen_iv_nuclear_energy_systems.pdf.

4. DOE-NE, The U.S. Generation IV Implementation Strategy, Department of Energy Office of Nuclear Energy, Science and Technology, September 2003.

5. 42 USC 14801, Energy Policy Act of 2005, (EPAct 2005), Federal Energy Regulatory Commission, August 8, 2005.

6. MPR-3181, "Survey of HTGR Process Energy Applications," Revision 0, MPR Associates, Inc., May 2008.

7. Richard D. Boardman, "Process Heat Applications Special Session," ASME International Topical Meeting on High Temperature Reactor Technology, Washington, D.C., October 1, 2008.

8. INL, Next Generation Nuclear Plant, Pre-Conceptual Design, INL/EXT-07-12967, Next Generation Nuclear Plant Project, Revision 1.

9. INL, Next Generation Nuclear Plant Technology Development Roadmaps: The Technical Path Forward, INL/EXT-08-15148, Next Generation Nuclear Plant Project, January 2009.

10. DOE M 413.3-1, "Project Management for the Acquisition of Capital Assets," Chapter 14, U.S. Department of Energy, March 2003.

11. NUREG/CR-6944, "Next Generation Nuclear Plant Phenomena Identification and Ranking Tables (PIRTS)," http://www.nrc.gov/reading-rm/doc-collections/nuregs/contract/cr6944/.

12. AREVA, "NGNP Conceptual Design DDN/PIRT Reconciliation," 12-9102279-001, February 2009.

13. General Atomics, "Reconciliation of NGNP DDNS with NRC PIRTS," September 2008.

14. Department of Energy, "Major Construction Projects need a Consistent Approach for Assessing Technology Readiness to Help Avoid Cost Increases and Delays," United States Government Accountability Office, GAO-07-336, March 2007, http://www.gao.gov/new.items/d07336.pdf.

15. Department of Energy, Uncertainties and Management Problems Have Hindered Cleanup at Two Nuclear Waste Sites, United States Government Accountability Office, GAO/T-RCED-00-248, July 12, 2000, http://www.gao.gov/archive/2000/rc00248t.pdf.

16. Electric Boat, Presentation made to NGNP Project Management and Reactor Suppliers, July 2008.

17. NUREG CR-6839, "Fort St. Vraine Gas-Cooled Reactor Operational Experience," Nuclear Regulatory Commission, January 2004.

18 M-6914-00-04, "Memo from Bob Varrin, Gerald Alder, and Ryan Jones to Richard Garrett, Component Test Facility Review, prepared by Dominion Engineering, Inc.," dated March 4, 2009. 
19. "U.S. Nuclear Regulatory Commission Long-Term Research: Fiscal Year 2009 Activities, Final Report," http://adamswebsearch.nrc.gov/idmws/ViewDocByAccession.asp?AccessionNumber= ML080150121, October 2007.

20. U.S. Department of Energy/Nuclear Power Industry Strategic Plan for Light Water Reactor Research and Development, INL/EXT-07-13543, November 2007, http://inlportal.inl.gov/portal/server.pt/gateway/PTARGS_0_8999_0_0_18/lwr_strategic_plan.pdf.

21. Westinghouse, "HTGR Component Test Facility Feasibility and Recommendations," NGNP-CTF, February 2008 
Appendix A

\section{Summary of Testing Requirements and Recommended Test Locations}




\section{Appendix A}

\section{Summary of Testing Requirements and Recommended Test Locations*}

(*) NOTE: In order to preserve the authenticity of the work performed by the system vendors, the following tables are reproduced verbatim from their reports. Any reference to a "component test facility" should be interpreted as a component test "capability," which refers to one or more facilities not currently available. 


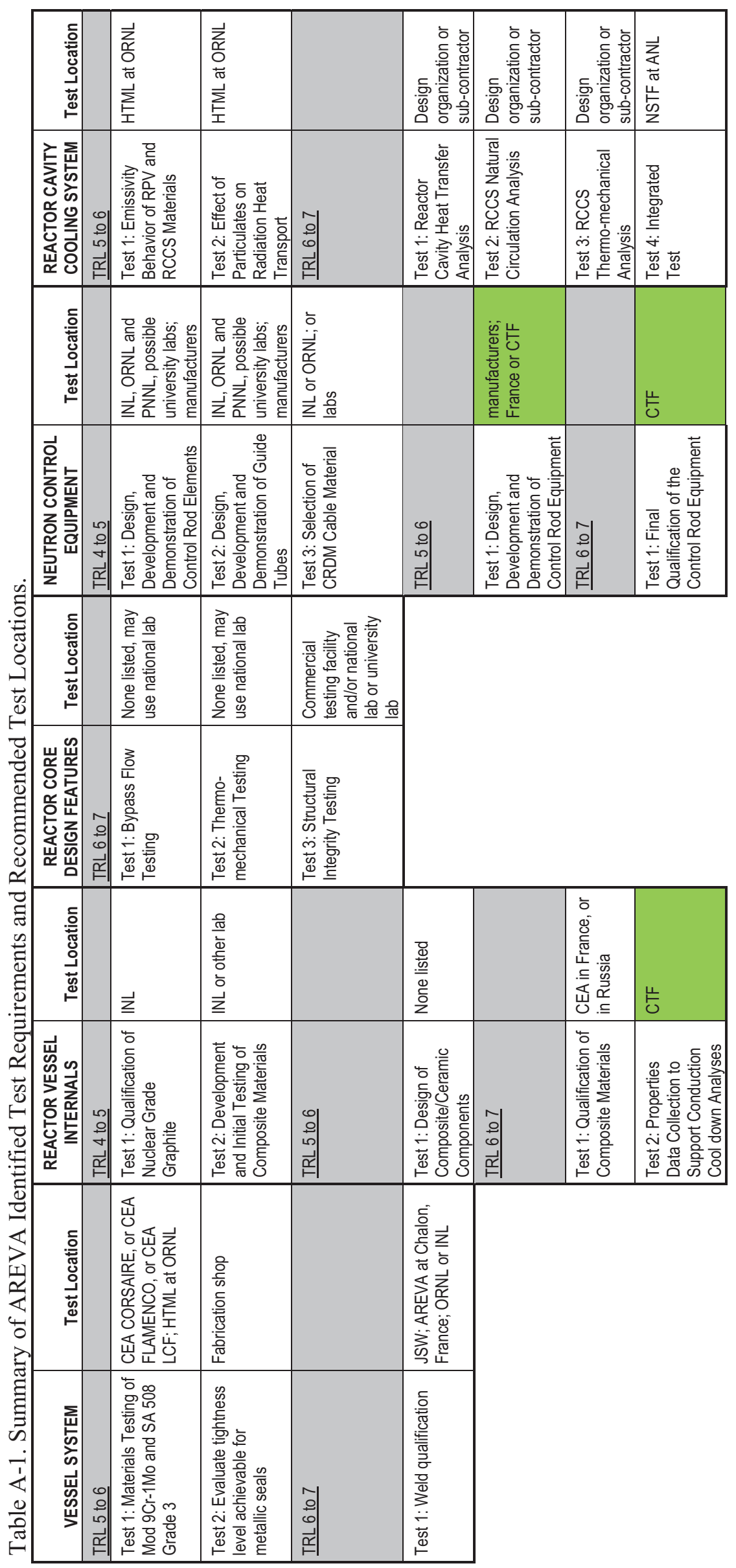




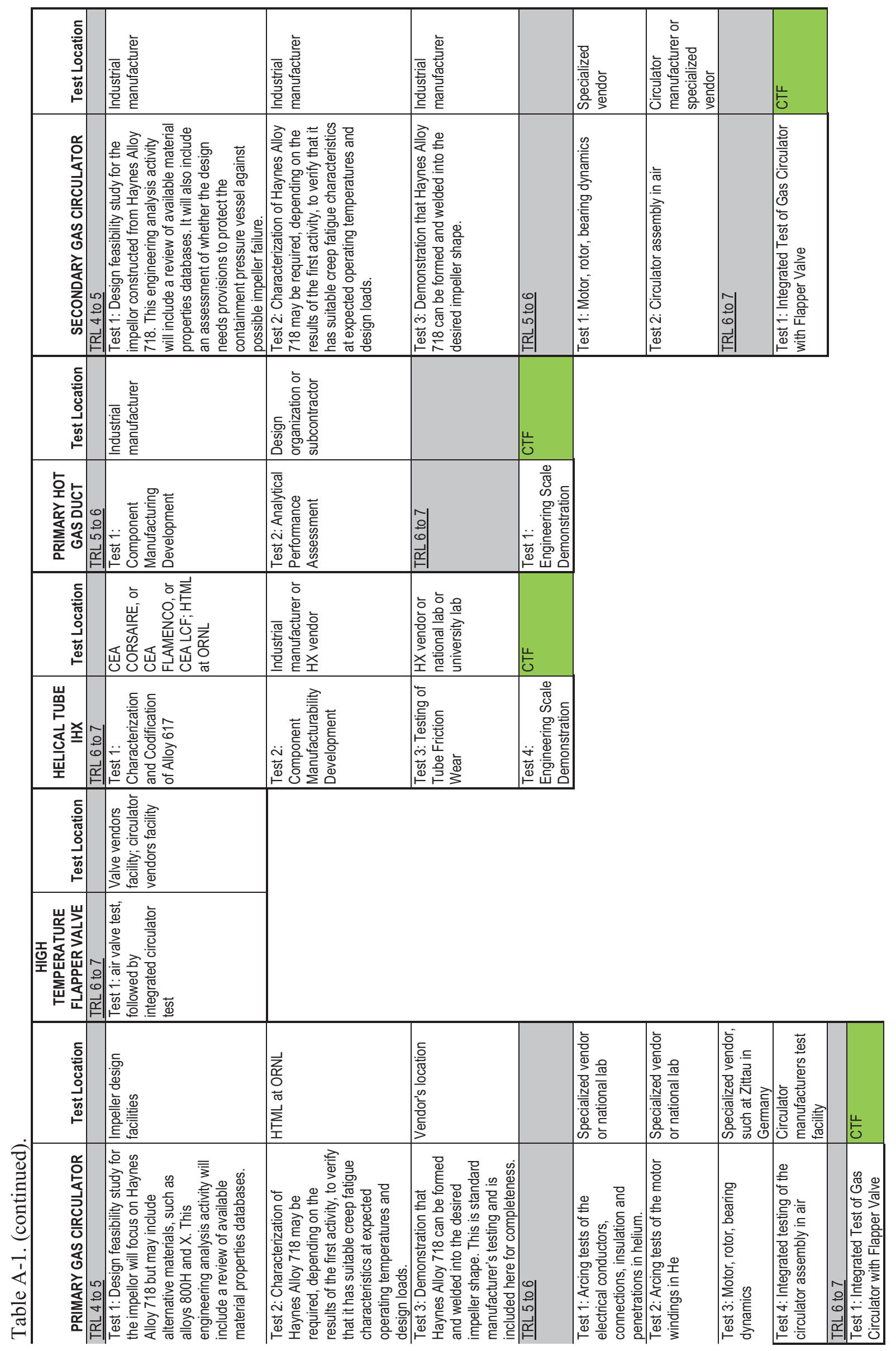




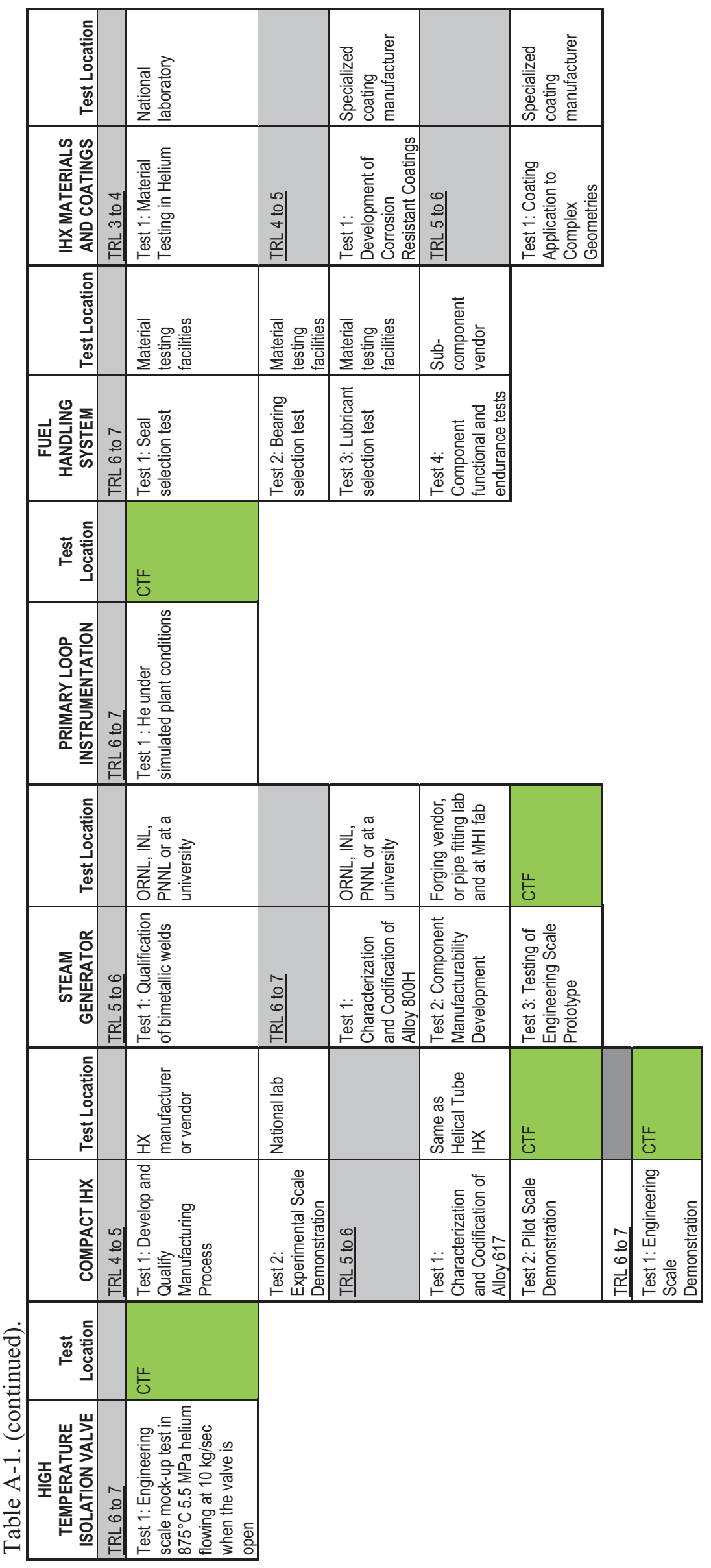




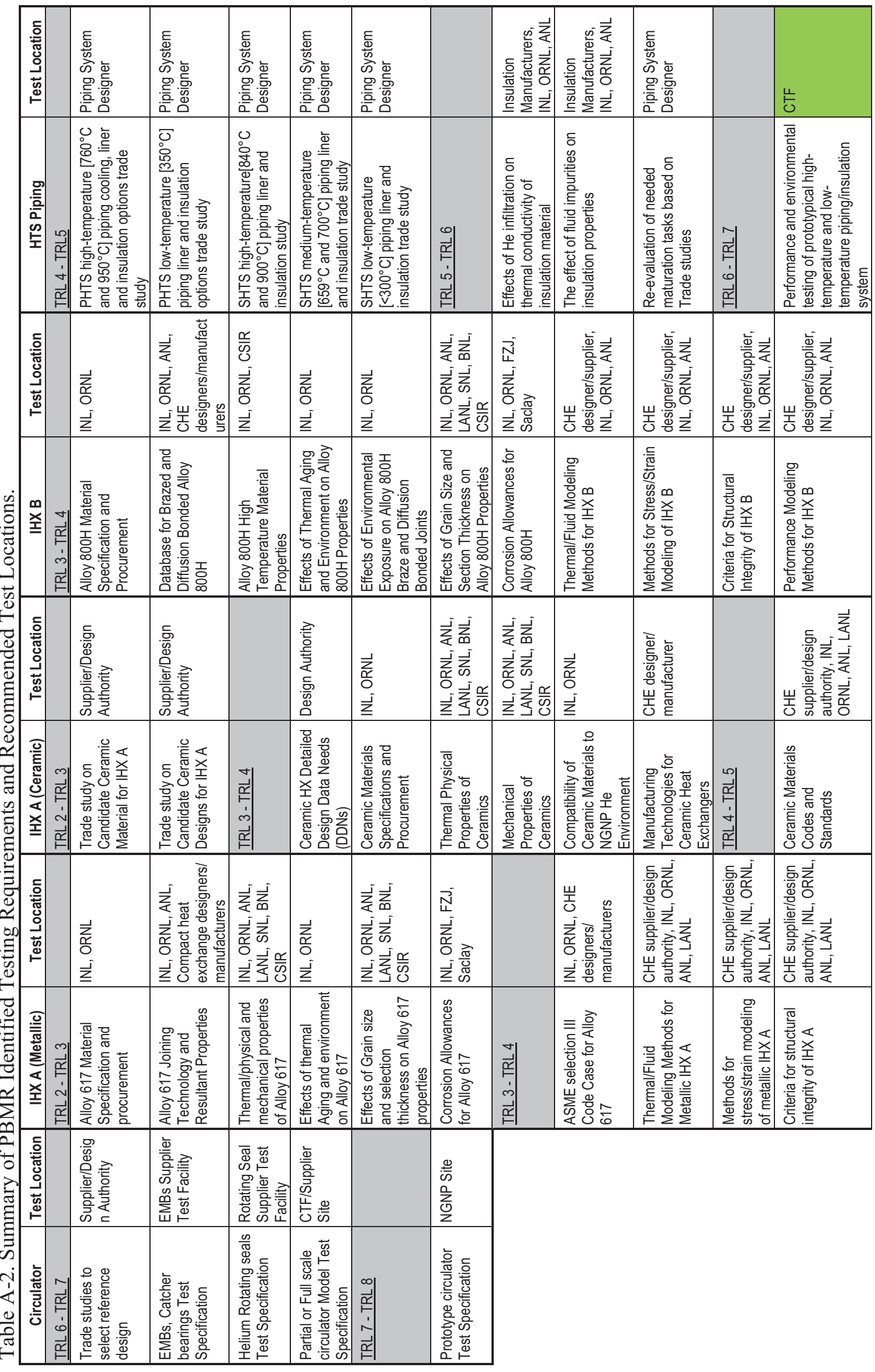




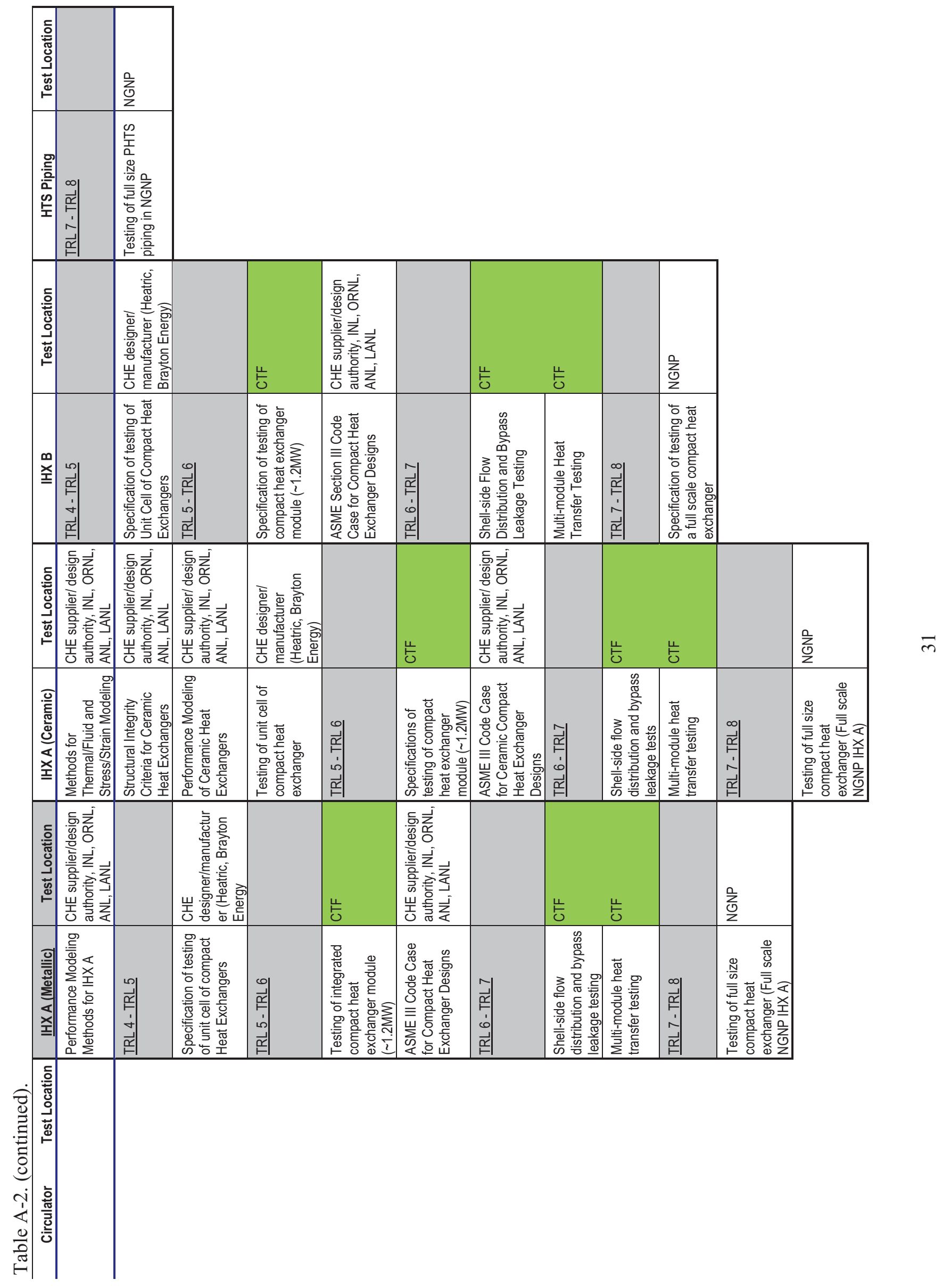




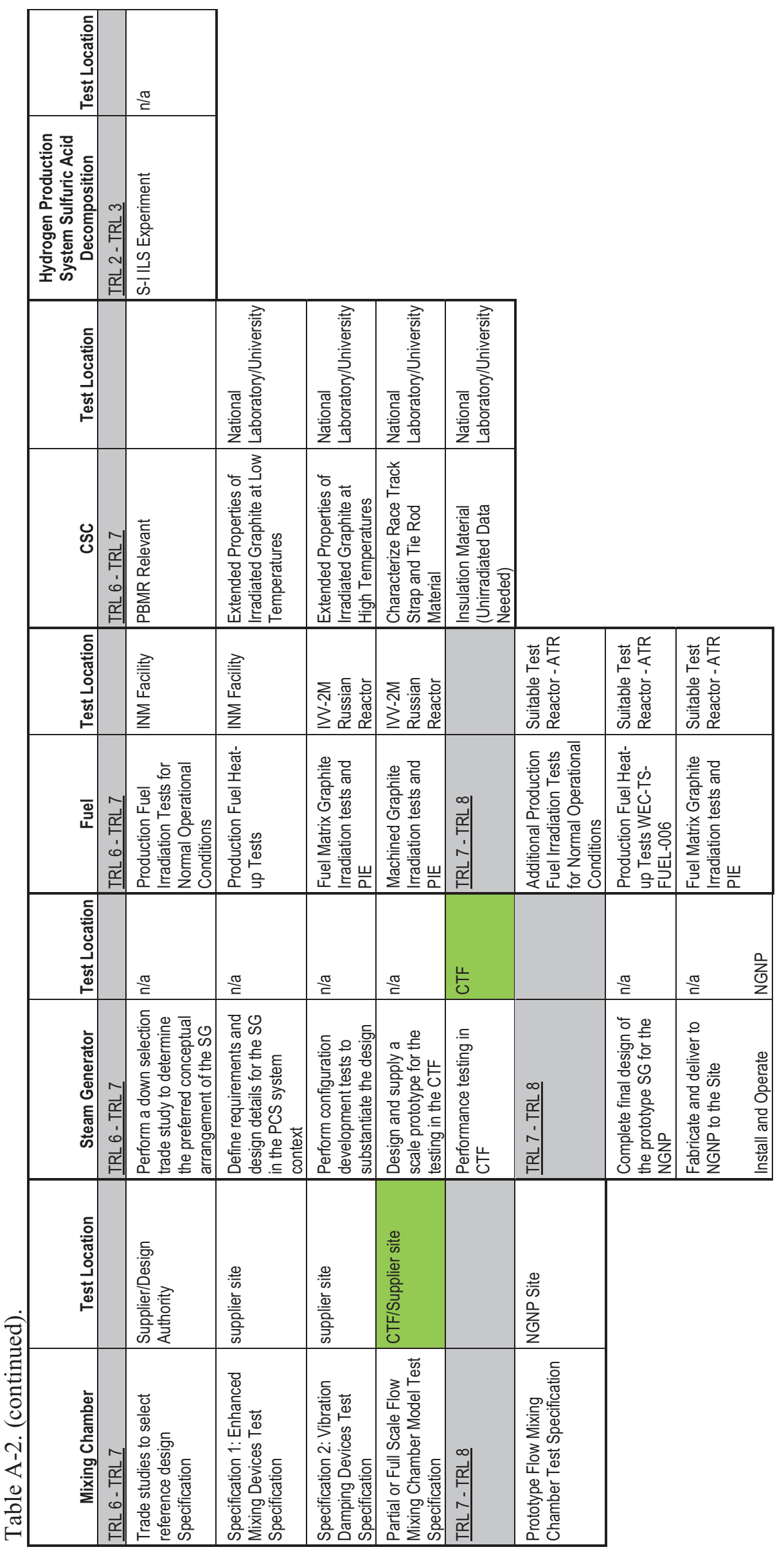




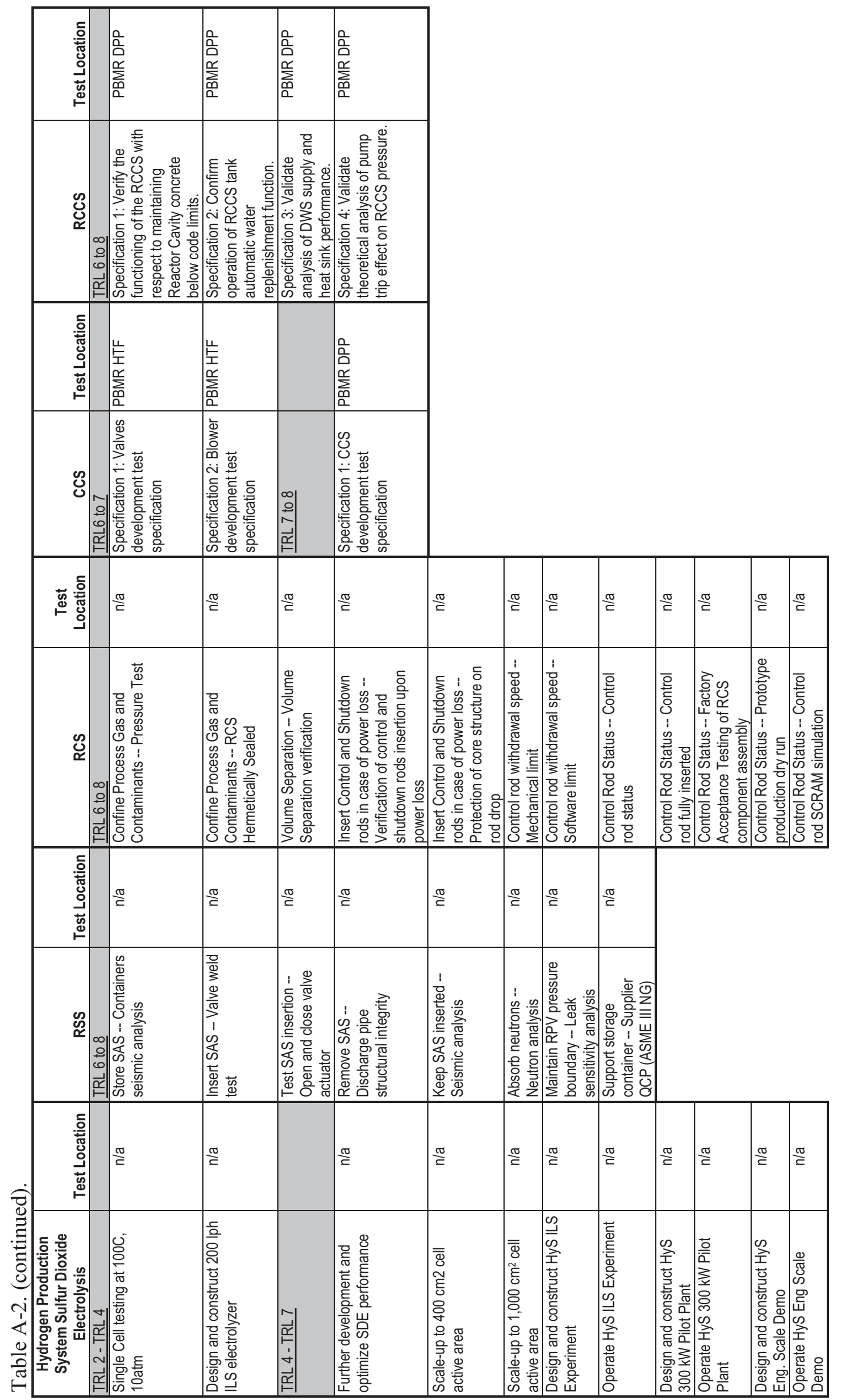




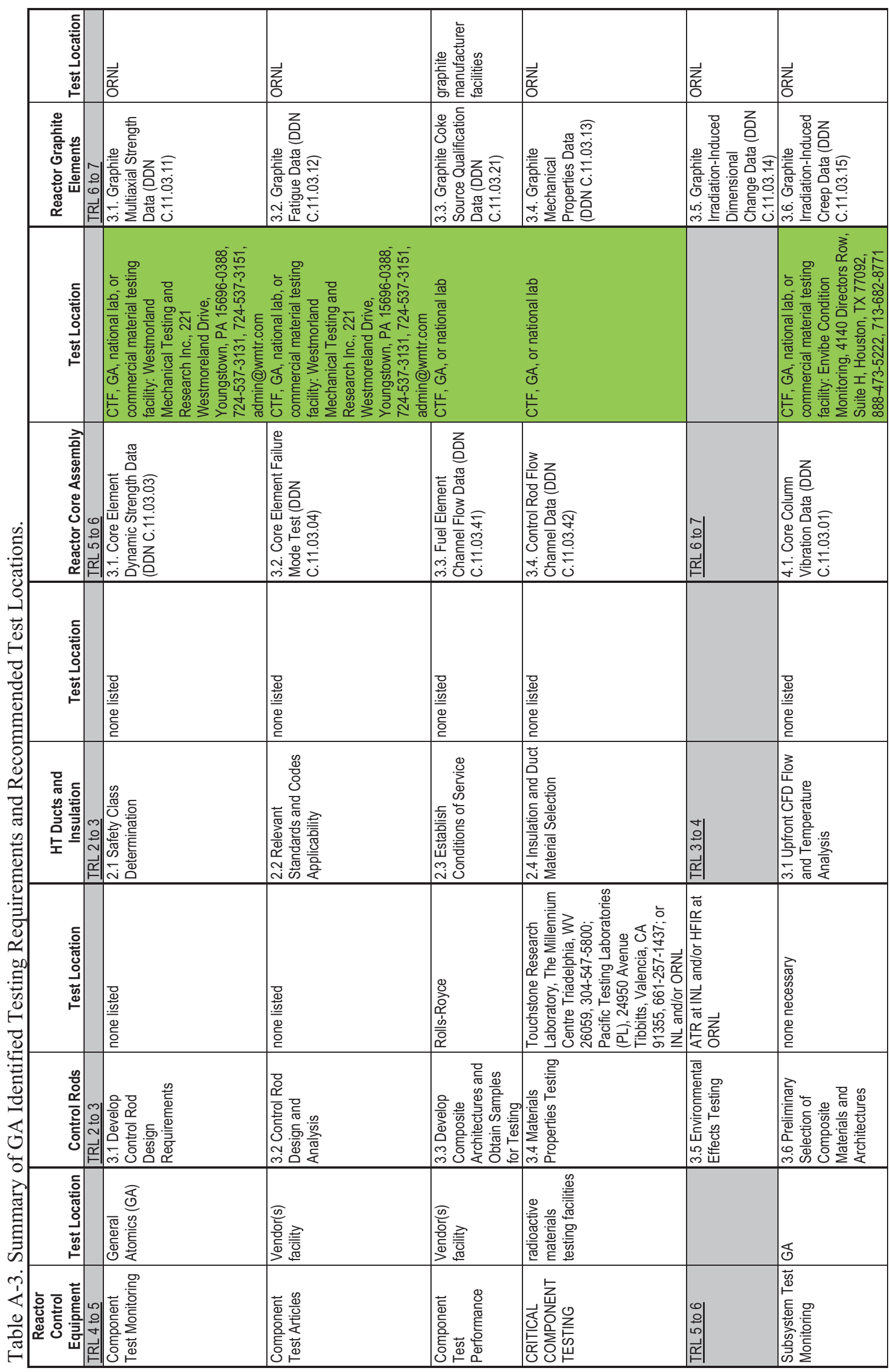




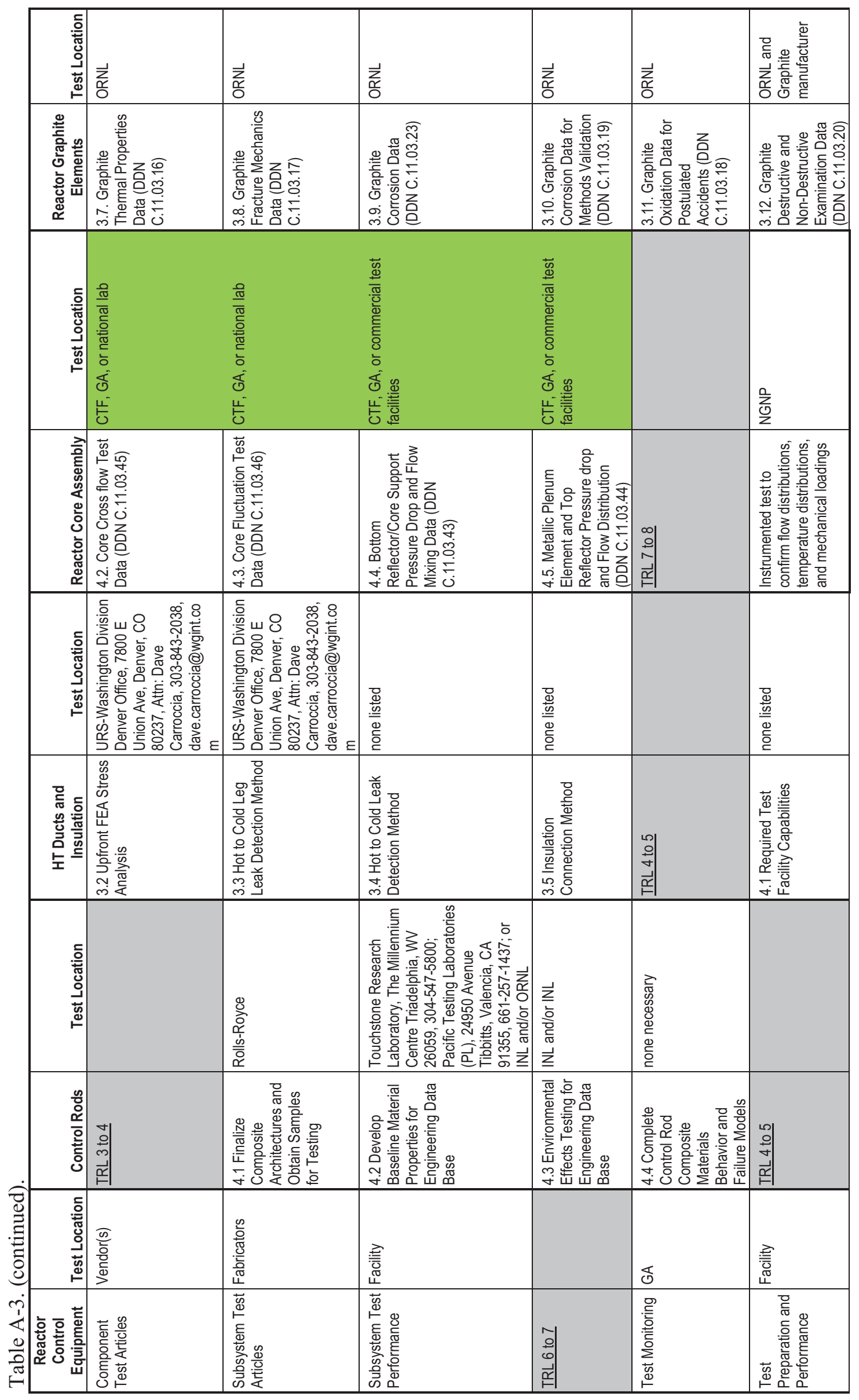




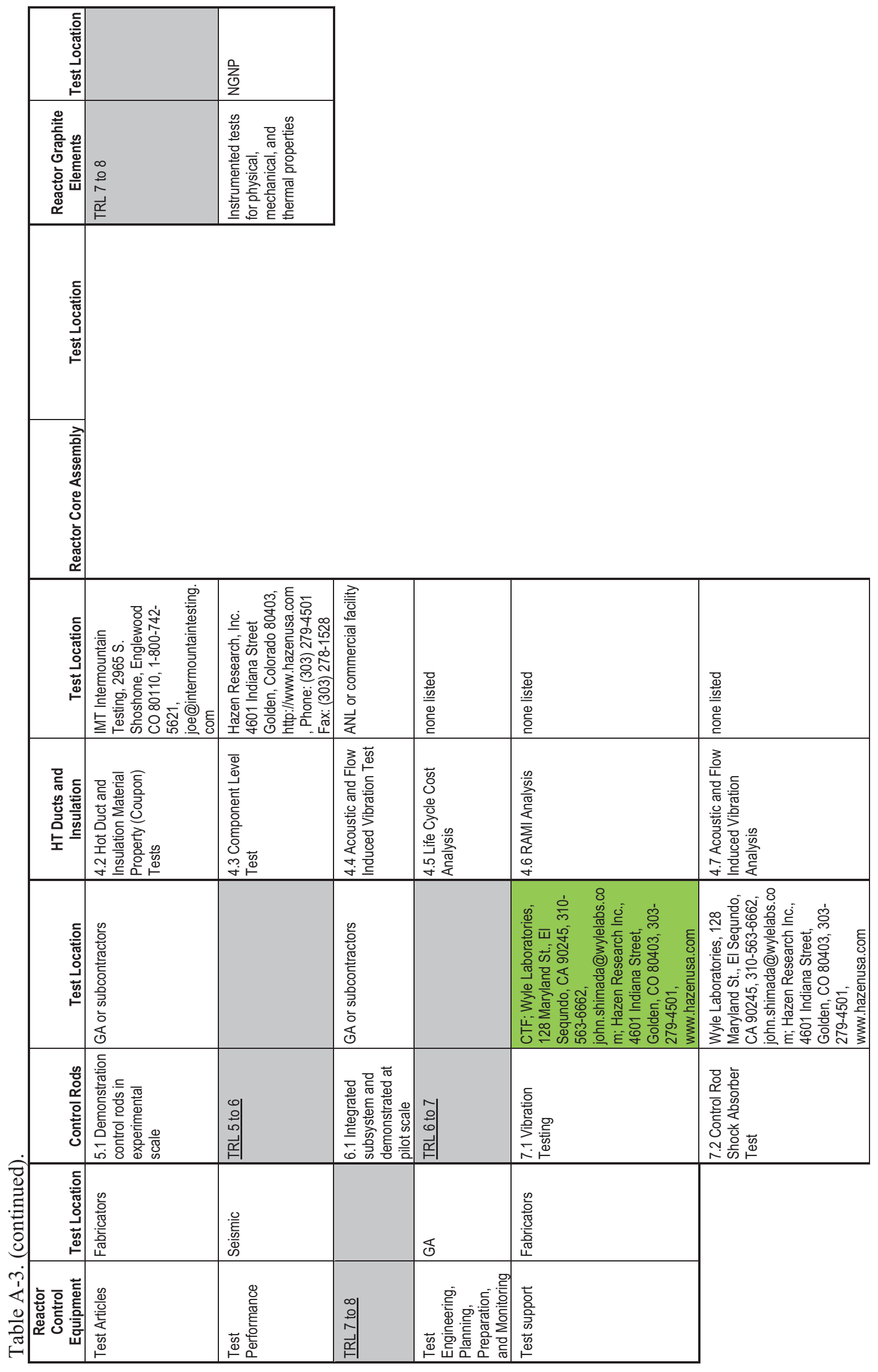




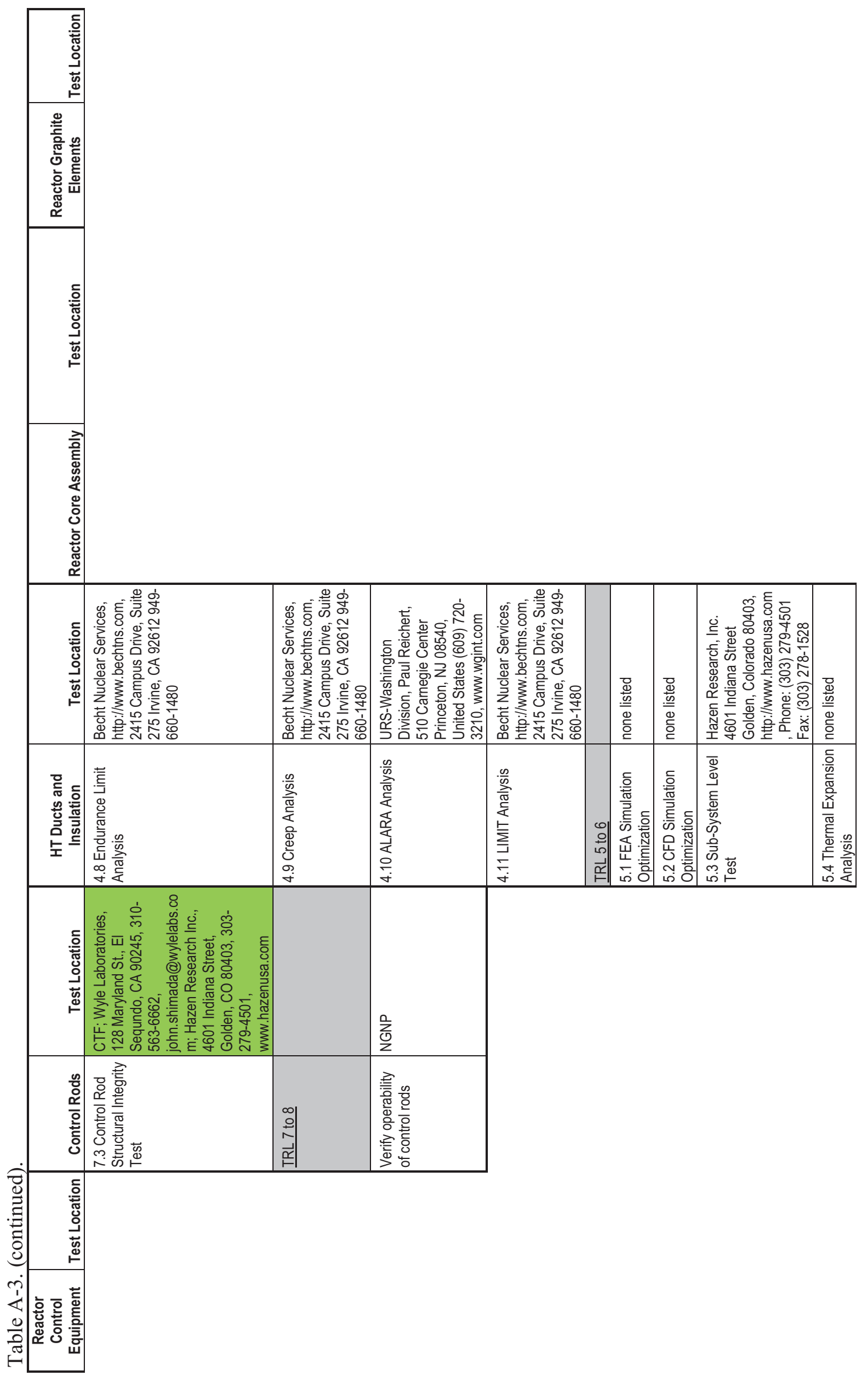




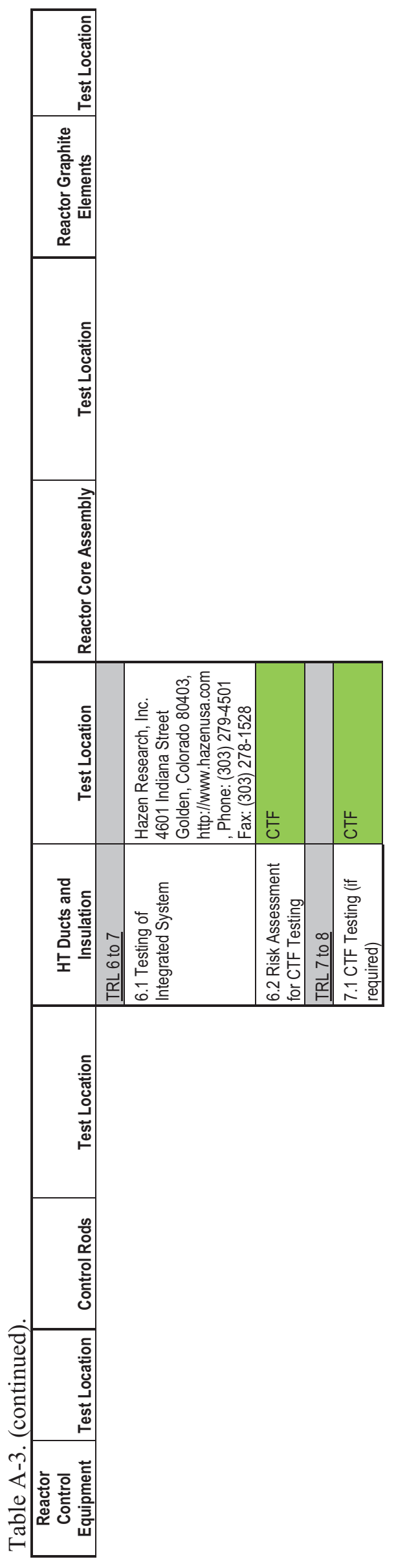


Table A-4. TRL definitions.

\begin{tabular}{|c|c|c|}
\hline $\begin{array}{l}\text { Rating } \\
\text { Level }\end{array}$ & Definition & Abbreviated Definition \\
\hline 1 & $\begin{array}{l}\text { Basic principles observed and reported in white papers, industry literature, } \\
\text { lab reports, etc. Scientific research without well defined application. }\end{array}$ & Basic principles observed \\
\hline 2 & $\begin{array}{l}\text { Technology concept and application formulated. Issues related to } \\
\text { performance identified. Issues related to technology concept have been } \\
\text { identified. Paper studies indicate potentially viable system operation. }\end{array}$ & Application formulated \\
\hline 3 & $\begin{array}{l}\text { Proof of concept: Analytical and experimental critical functions and/or } \\
\text { characteristic proven in laboratory. Technology or component tested at } \\
\text { laboratory scale to identify/screen potential viability in anticipated service. }\end{array}$ & Proof of concept \\
\hline 4 & $\begin{array}{l}\text { Technology or component is tested at bench scale to demonstrate } \\
\text { technical feasibility and functionality. For analytical modeling, use generally } \\
\text { recognized benchmarked computational methods and traceable material } \\
\text { properties. }\end{array}$ & Bench scale testing \\
\hline 5 & $\begin{array}{l}\text { Component demonstrated at experimental scale in relevant environment. } \\
\text { Components have been defined, acceptable technologies identified and } \\
\text { technology issues quantified for the relevant environment. Demonstration } \\
\text { methods include analyses, verification, tests, and inspection. }\end{array}$ & $\begin{array}{l}\text { Component verified at } \\
\text { experimental scale }(1 / 1,000)\end{array}$ \\
\hline 6 & $\begin{array}{l}\text { Components have been integrated into a subsystem and demonstrated at a } \\
\text { pilot scale in a relevant environment }\end{array}$ & $\begin{array}{l}\text { Subsystem verified at pilot } \\
\text { scale }(1 / 100)\end{array}$ \\
\hline 7 & $\begin{array}{l}\text { Subsystem integrated into a system for integrated engineering scale } \\
\text { demonstration in a relevant environment. }\end{array}$ & $\begin{array}{l}\text { System demonstration at } \\
\text { engineering scale }(1 / 20)\end{array}$ \\
\hline 8 & $\begin{array}{l}\text { Integrated prototype of the system is demonstrated in its operational } \\
\text { environment with the appropriate number and duration of tests and at the } \\
\text { required levels of test rigor and quality assurance. Analyses, if used, } \\
\text { support extension of demonstration to all design conditions. Analysis } \\
\text { methods verified and validated. Technology issues resolved pending } \\
\text { qualification (for nuclear application, if required). Demonstrated readiness } \\
\text { for hot startup. }\end{array}$ & $\begin{array}{l}\text { Integrated prototype tested } \\
\text { and qualified ( } 1 / 4 \text { scale) }\end{array}$ \\
\hline 9 & $\begin{array}{l}\text { The project is in final configuration tested and demonstrated in operational } \\
\text { environment. }\end{array}$ & Plant operational \\
\hline 10 & $\begin{array}{l}\text { Commercial-scale demonstration is achieved. Technological risks } \\
\text { minimized by multiple units built and running through several years of } \\
\text { service cycles. }\end{array}$ & $\begin{array}{l}\text { Commercial scale - multiple } \\
\text { units }\end{array}$ \\
\hline
\end{tabular}




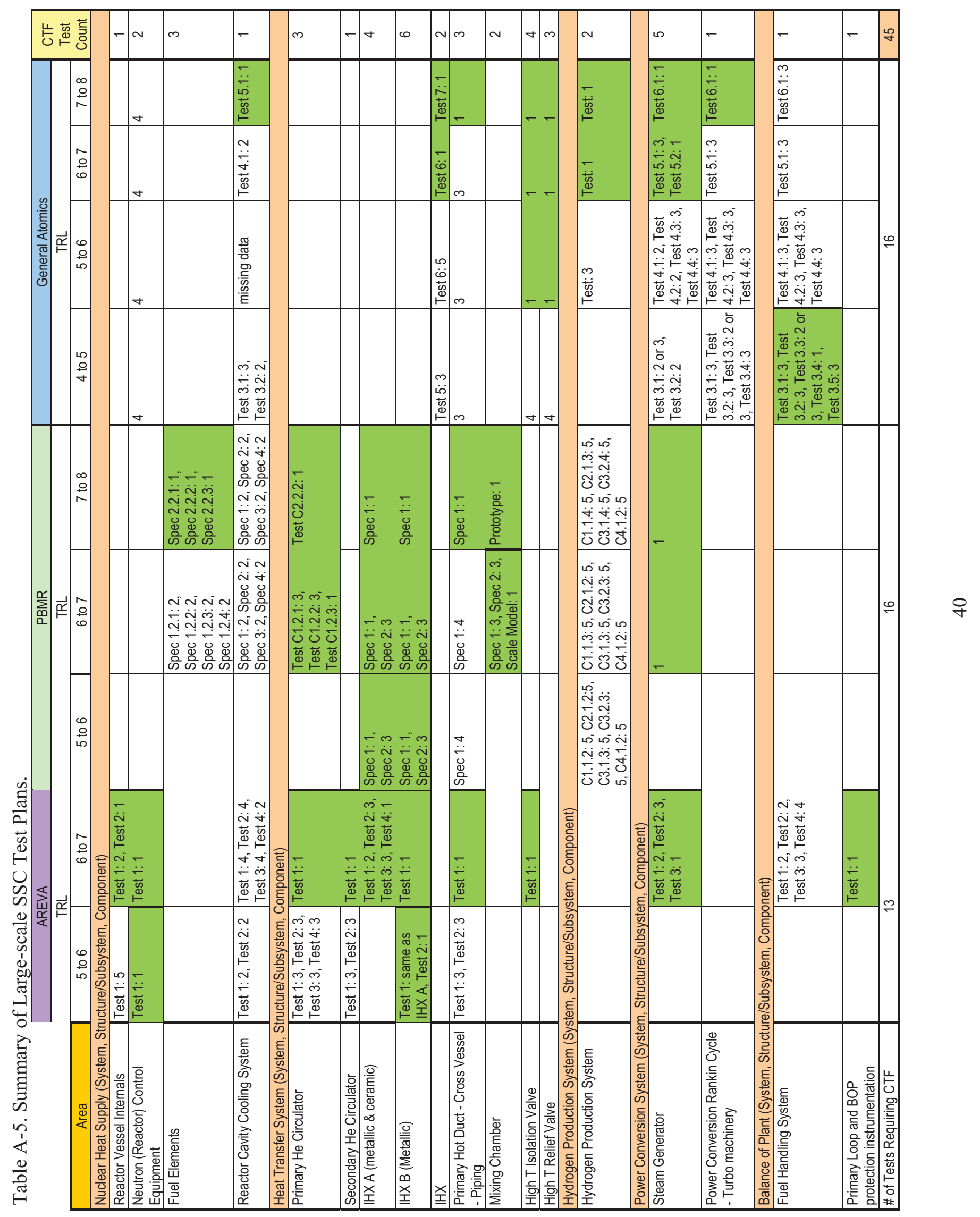


Appendix B

Hybrid Energy Systems Testing Laboratory (HYTEST) 


\section{Appendix B}

\section{Hybrid Energy Systems Testing Laboratory (HYTEST)}

The integration of novel technologies into operating, safe, robust, and trusted and accepted systems from a regulatory perspective; the retooling and realignment of existing systems to be more efficient energy producers, and getting the "the right energy, in the right place, at the right time" requires a systems design, analysis, and optimization approach coupled with point technology innovation. Integrating components into systems, and systems into systems of systems, will make it possible to simultaneously address energy security market drivers (economics, environment, resource security).

The overall focus of hybrid systems is the effective, efficient use of energy in the production of marketable products. Subsystem (component) technical challenges associated with this objective include 5 broad categories, or platforms:

- Feedstock Processing, including resource extraction, and supply

- Heat Transfer/Energy Integration

- Byproduct Management

- Product Synthesis

- System Monitoring, Diagnostics, and Controls.

The Idaho National Laboratory proposes to develop a laboratory (or set of laboratories) dedicated to development, testing, and demonstration of component, subsystem, and systems comprised of combinations of these 5 elements. This laboratory will be called the Hybrid Systems Testing Laboratory, or HYTEST.

The purpose (products) of this laboratory will be to acquire performance data, identify scalability issues, quantify technology gaps and needs for various "hybrid" or other energy systems, and provide infrastructure to develop solutions in each of the 5 platforms. It is key to note that the HYTEST lab can drive sales involving hybrid system designs, as well as marketable products supporting elements such as diagnostics and control, heat transfer systems, catalysts, etc. Therefore, HYTEST is a capability to (1) Develop a new market for advanced integrated (hybrid) energy systems and (2) Develop products for existing component and system markets.

INL HYTEST program will effectively carry new technology applications and systems integration concepts through DOE Technology Readiness Levels (TRL) by establishing testing and demonstration laboratories at three locations. In FY-09, INL will setup and integrate lab and bench scale components for each of the four functional test areas at the Bonneville County Testing Center (BCTC) and the Idaho Engineering Develop Facility (IEDF). These two facilities will provide laboratory space to meet TRL levels 1-3 for each of the functional area. A $15 \mathrm{kWe}$ Integrated Lab Scale (ILS) high temperature steam electrolysis (HTSE) bench-scale test unit was setup and demonstrated in FY-08. Small scale heat exchanger and materials testing and qualification can be conducted in this lab using electrical heaters and steam generation units already in place with the ILS. Approximately $800 \mathrm{ft}^{2}$ of laboratory space is available at BCTC for laboratory-scale component development and integration testing.

IEDF is a substantially larger HYTEST laboratory. With over $2,000 \mathrm{ft}^{2}$ of floor space, a high-bay ceiling of $30 \mathrm{ft}$, a 20 -ton overhead rail crane, and ample electrical, natural gas, compressed air, industrial ventilation and off-gas collectors and blowers, this facility will serve as an area to conduct TRL testing through Level 4. This area is sufficient for bench-scale testing of NGNP heat exchangers, heat transfer loops, integrated hydrogen generation, and associated hybrid energy equipment development, testing, and 
verification. A dedicated control system will permit the development of advance control systems necessary for monitoring and control of larger scale systems. Multi-stage flammable compressors, gas and liquid product storage tanks, and gas dilution/gas flare are being installed at the IEDF to enable a wide variety of hybrid energy test operations to be conducted. The support equipment will enable NGNP component testing to be completed using poisonous gas mixtures $(\mathrm{He}-\mathrm{CO})$ and pressurized inert gas $\left(\mathrm{CO}_{2}, \mathrm{He}, \mathrm{N}_{2}\right)$ that require adequate laboratory ventilation to mitigate asphyxiation risks.

A larger, reconfigurable, bench-scale (or small pilot scale) process demonstration unit (PDU) HYTEST facility will be established for cost effective component and component integration testing prior to construction and operation of larger pilot plant components using the NGNP Component Test Capability (CTC). This HYTEST PDU facility will be scaled to match the $200 \mathrm{KWe}$ hydrogen HTSE unit planned for development and testing under the National Hydrogen Initiative. HYTEST PDU is intended to test a variety of components and integrated components to attain TRL Levels 3 and 4. Some components developed at IEDF will be moved to the PDU where they can be integrated with other new test components forming a specific bench-scale integrated process test prototype. HYTEST PDU will, however, not be relegated to any single configuration, but will be flexible to investigate several components and integrated systems as program priorities and industrial user's interests apply. Also of significant importance, HYTEST PDU will provide a platform for development of new instruments, monitors, and control systems for hybrid energy systems component and component integrations at the CTC.

The CTC will provide process heat and power to operate the 2 MWe HTSE unit in the NHI project plan. This unit will produce sufficient hydrogen to supplement hybrid testing of a 70 ton per day coal or biomass gasifier integrated with a 200 barrel per day synthetic liquid fuels reactor. These reactor sizes are commensurate with pilot plant operations elsewhere, and are considered are adequate to provide data for engineering-scale demonstrations. The CTC will thus extend the development of hybrid energy components and systems to TRL Levels 7.

In addition to hydrogen and oxygen supply from HTSE, hybrid energy systems will rely on heat transfer from components emulating NGNP heat sources. It is important that heat transfer, mass action, and transport phenomena be tested in an integrated facility to identify and resolve technical integration issues; for example, startup and shutdown dynamics, transient process behavior, instrumentation, data monitoring, and process control logic for highly coupled and interdependent processes. Integrated process operations may require test durations of 1,000 to 2,000 hours in order to demonstrate the process stability and reliability necessary for large industrial investment commitment. Integrated testing will provide crucial operating training necessary for startup of the new systems. Finally, integration with envisioned HYTEST operation with NGNP component testing is the most cost effective manner for testing many hybrid energy systems. In order to support the potential hybrid energy system testing activities, the following CTC are needed:

1. Heat transfer loop connection to service pilot-scale HYTEST component demonstrations for continuous operation over long test periods

2. Electrical service connections to simulate nuclear reactor electricity or renewable energy electricity that is used to power hybrid energy systems

3. Hydrogen and oxygen storage tanks, compressors, and high pressure service pipes that can be accessed by hybrid energy systems.

4. Hydrogen, oxygen, and by-product gas and liquid storage tanks.

5. Process monitoring and controls center sufficient for multiple component testing, as well as integrated system testing. 
6. Physical structures sufficient to locate and test multiple pilot-scale operations set in proximity for transfer of energy, products, and by-products.

7. Accessibility by train or heavy truck to deliver solid feedstock materials or to remove bulk quantities of liquid or gaseous product.

8. Utilities, including water, natural gas, electricity, steam, compressed air, etc., to supply multiple components.

9. Engineers and operators offices, fire safety, and life support systems.

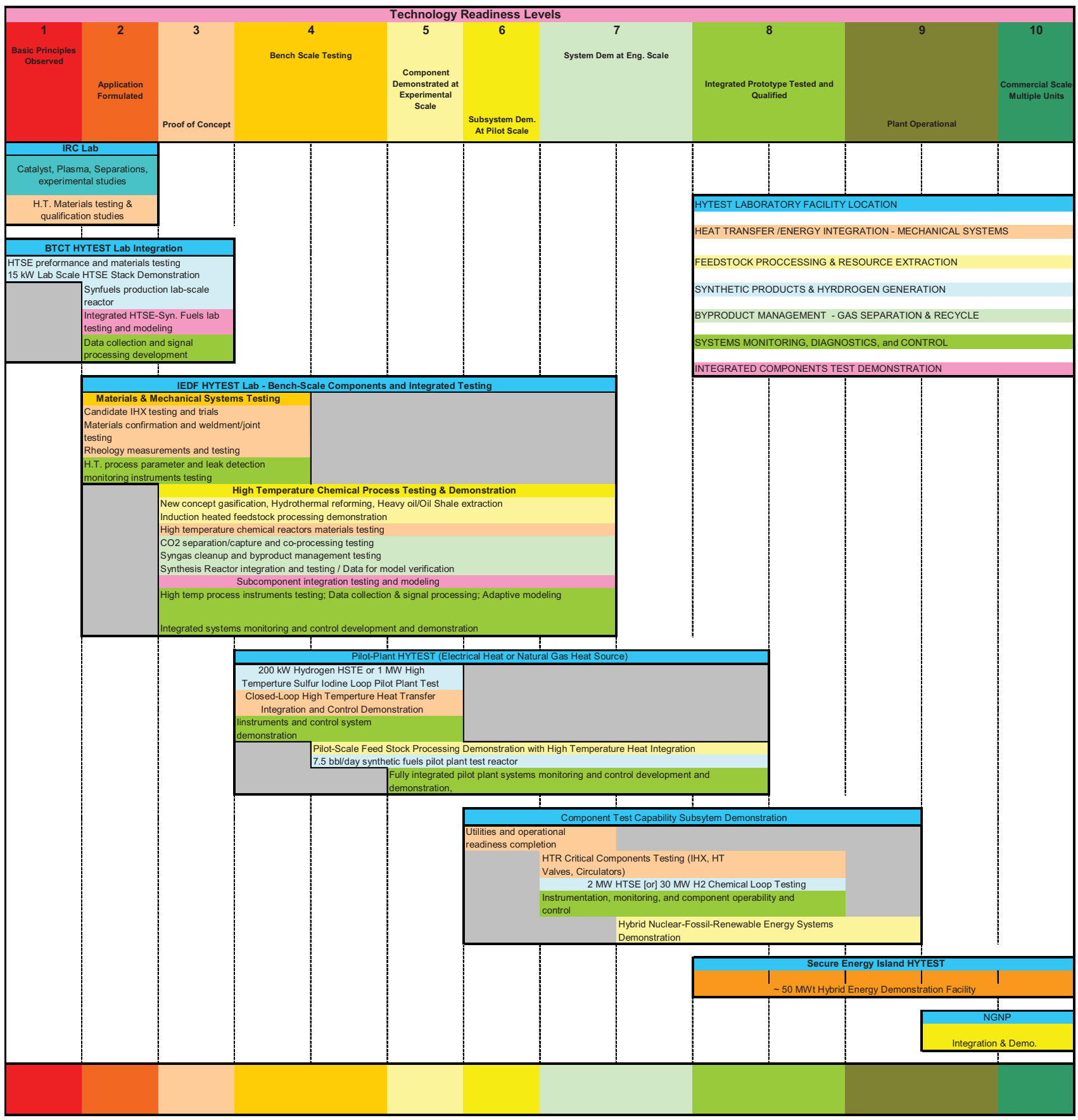


Appendix C

\section{Example of TDRM}




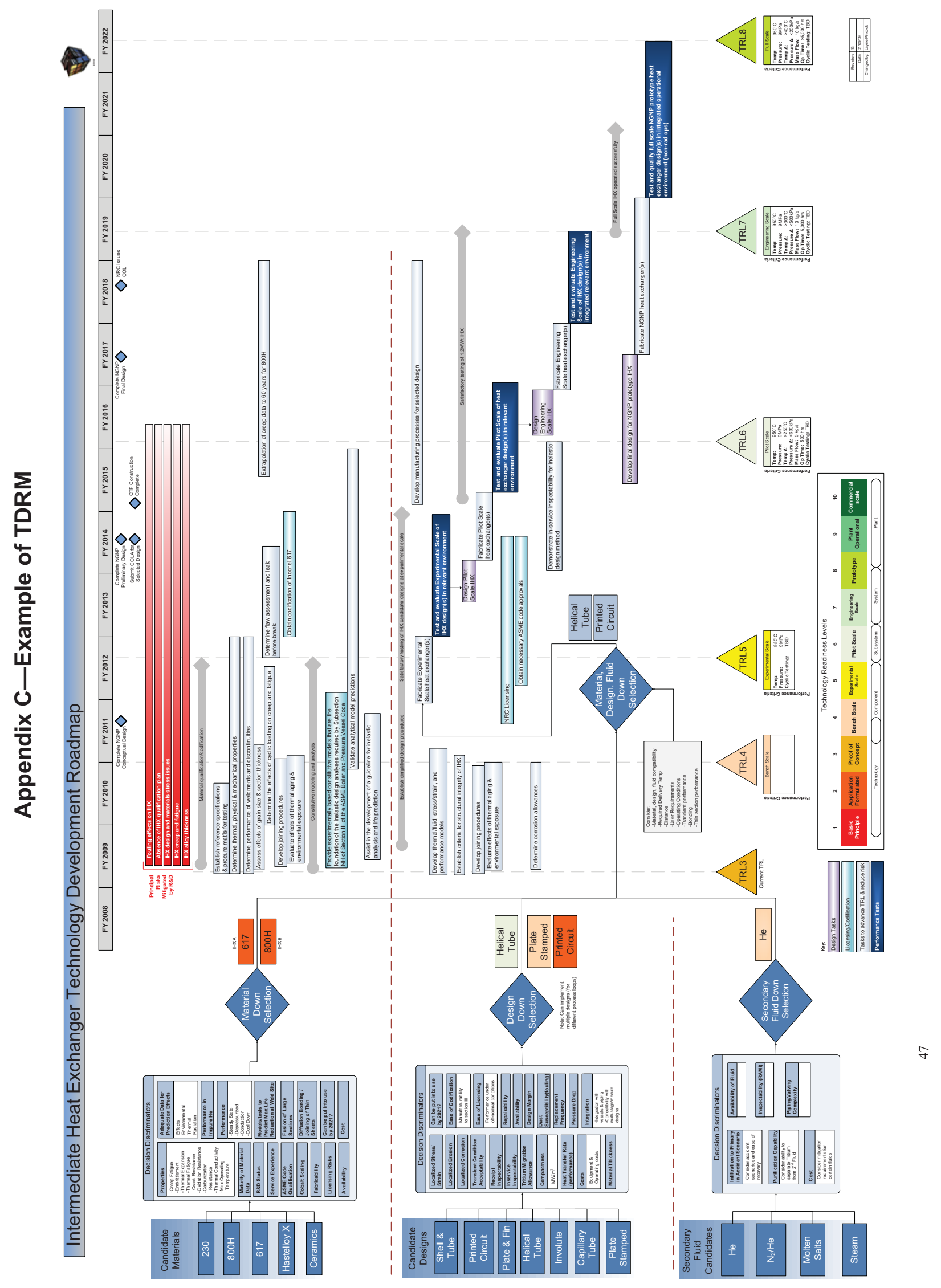

